Supporting Information

\title{
Conjugated Copolymers of Poly(arylenevinylene)s: Synthesis by Ring-Opening Metathesis Polymerization, Film Morphology, and Resonant Luminescence from Microspheres
}

\author{
Yen-Jen Lin, ${ }^{\dagger}$ Hsin-Yu Chiang, ${ }^{\dagger}$ Osamu Oki,${ }^{\ddagger}$ Soh Kushida, ${ }^{\dagger}$ Shu-Wei Chang, ${ }^{\dagger}$ Shih- \\ Ting Chiu, ${ }^{\dagger}$ Yohei Yamamoto, ${ }^{*},+$ Takuya Hosokai, ${ }^{\S}$ and Masaki Horie ${ }^{*}, \dagger$ \\ ${ }^{\dagger}$ Department of Chemical Engineering, National Tsing Hua University, 101, Sec. 2, Kuang-Fu Road, \\ Hsinchu 30013, Taiwan. \\ ${ }^{\star}$ Department of Materials Science and Tsukuba Research Center for Energy Materials Science \\ (TREMS), Faculty of Pure and Applied Sciences, University of Tsukuba, 1-1-1 Tennodai, Tsukuba, \\ Ibaraki 305-8573, Japan. \\ $\S$ National Metrology Institute of Japan (NMIJ), National Institute of Advanced Industrial Science and \\ Technology (AIST), Tsukuba Central 2, 1-1-1 Umezono, Tsukuba, Ibaraki 305-8568, Japan.
}

\section{Corresponding Authors}

*E-mail: mhorie@mx.nthu.edu.tw and yamamoto@ims.tsukuba.ac.jp 


\section{Experimental section}

\subsection{General methods.}

Second- and third generation Grubbs catalysts, Zinc powder and pyridine were purchased from Sigma-Aldrich. Hexane, dichloromethane, chloroform, and THF were purchased from J.T. Baker. $\mathrm{TiCl}_{4}$ was purchased from Honeywell International Inc. All chemicals were used as purchased from commercial companies. Monomers CPDT- $t$ and DTBT- $t$ and polymer P4 were synthesized by reported methods. ${ }^{\mathrm{S} 1}$ Synthesis was performed under a nitrogen atmosphere using standard Schlenk techniques. Compounds were purified by preparative size exclusion chromatography (SEC) using JAI LC-9204 with a column GAIGEL-1H-40 eluted with chloroform.

The molecular weights of the polymers were determined by gel permeation chromatography (GPC) using a JASCO 870 UV detector, a 880 pump, and American Polymer Standards Corporation ultrastyragel columns (Serial 2-15-89 A, B, and C) eluted with tetrahydrofuran (THF) as the solvent and polystyrene was used as the standard. ${ }^{1} \mathrm{H}$ NMR spectra were obtained using a Bruker $500 \mathrm{MHz}$ spectrometer. UVvis absorption spectra were recorded on a JASCO V-630 UV-vis spectrophotometer. Cyclic voltammetry was performed at $0.10 \mathrm{~V} \mathrm{~s}^{-1}$ in a DY2300 electrochemical analyzer with a three-electrode cell, $\mathrm{AgCl} / \mathrm{Ag}$ as reference electrode, platinum wire as counter electrode, and platinum plate as the working electrode in nitrogen-purged anhydrous $0.10 \mathrm{M}$ tetrabutylammonium hexafluorophosphate $\left(n-\mathrm{Bu}_{4} \mathrm{NPF}_{6}\right)$ acetonitrile solution at room temperature. The polymer films were prepared from $\mathrm{CHCl}_{3}$ solution of the polymers by drop casting onto the platinum plates. Onset of an oxidation peak potential was used in the calculation of HOMO energy level. AFM were estimated by PARKsystems XE-70. Thin films of the polymers were prepared by spin coating (1500 rpm for 50 seconds) from a chloroform solution (1 wt\%) on a glass substrate. GISAXS/WAXS measurements were conducted at the 23A SWAXS end station of the National Synchrotron Radiation Research Center, Taiwan. Sample thin films were respectively placed horizontally on a sample stage. With a $15 \mathrm{keV}$ (wavelength $\lambda=$ $1.2398 \AA$ ) beam and an incident angle $0.2^{\circ}$, GISAXS/WAXS patterns were collected using a Pilatus $1 \mathrm{M}-\mathrm{F}$ area detector situated $5015 \mathrm{~mm}$ from the sample position. The scattering wavevector, defined as $q=4 \pi \lambda^{-1} \sin \theta$ (with $2 \theta$ the scattering angle), was calibrated using silver behenate.

\section{$1.2 \mu$-Photoluminescence measurements.}

$\mu$-PL measurements of single microspheres with ps-laser pumping were carried out using a $\mu$-PL measurement system. An optical microscope was used with a long- 
distance $100 \mathrm{x}$ objective $(\mathrm{NA}=0.8)$ to identify suitable particles and determine their diameters $(d)$. For the measurements, a WITec $\mu$-PL system was used with a model Alpha 300S microscope combined with a Princeton Instruments model Acton SP2300 monochromator (grating: 300 and 1200 grooves $\mathrm{mm}^{-1}$ ) and an Andor iDus model DU401A BR-DD-352 CCD camera cooled to $-60{ }^{\circ} \mathrm{C}$. The perimeter of a single microsphere was photoexcited at $25{ }^{\circ} \mathrm{C}$ under ambient conditions by a diode pulsed laser (PicoQuant model LDH-D-C-470B with a PDL 828 'Sepia II' driver) with a wavelength $(\lambda \mathrm{ex})$, power, integration time, frequency $(f)$, pulse duration $(\Delta)$, and spot size of $470 \mathrm{~nm}, 1.5 \mu \mathrm{W}, 0.1 \mathrm{~s}, 2.5 \mathrm{MHz}, 70 \mathrm{ps}$, and $\sim 0.5 \mu \mathrm{m}$, respectively.

\section{Reference}

(S1) Chang, S.-W.; Horie, M. A Donor-Acceptor Conjugated Block Copolymer of Poly(arylenevinylene)s by Ring-Opening Metathesis Polymerization. Chem. Commun. 2015, 51, 9113-9116. 


\section{Synthesis}

Table S1. Results of McMurry coupling for the synthesis of BT- $\boldsymbol{d}$ and BT-t.

\begin{tabular}{cccccccc}
\hline Entry & Solvent & $\begin{array}{c}\text { Concentration } \\
(\mathrm{M})\end{array}$ & $\begin{array}{c}\text { Temp. } \\
\left({ }^{\circ} \mathrm{C}\right)\end{array}$ & $\begin{array}{c}\text { Time } \\
(\mathrm{hr})\end{array}$ & $\begin{array}{c}\text { Injection } \\
\text { rate } \\
(\mathrm{mL} / \mathrm{min})\end{array}$ & $\begin{array}{c}\text { BT- } \boldsymbol{d} \\
\text { yield } \\
(\%)\end{array}$ & $\begin{array}{c}\text { BT- } \boldsymbol{t} \\
\text { yield } \\
(\%)\end{array}$ \\
\hline $\mathbf{1}$ & THF & 0.0054 & 75 & 1 & $1000^{[\mathrm{a}]}$ & 7 & 12 \\
$\mathbf{2}$ & THF & 0.01 & 55 & 1 & $0.3^{[\mathrm{b}]}$ & 16 & 14 \\
$\mathbf{3}$ & THF & 0.02 & 75 & 1 & $1000^{[\mathrm{a}]}$ & 6 & 13 \\
$\mathbf{4}$ & THF & 0.02 & 55 & 1 & $0.3^{[\mathrm{b}]}$ & 22 & 14 \\
$\mathbf{5}$ & THF & 0.04 & 55 & 1 & $0.3^{[\mathrm{b}]}$ & $\mathrm{N} / \mathrm{A}^{[\mathrm{c}]}$ & $\mathrm{N} / \mathrm{A}^{[\mathrm{c}]}$ \\
\hline
\end{tabular}

[a] THF solution of the reactant was injected into THF solution of $\mathrm{TiCl}_{4} / \mathrm{Zn}$. [b] THF solution of the reactant was injected into THF solution of $\mathrm{TiCl}_{4} / \mathrm{Zn}$ using an autoinjector. [c] The solution became gel after addition of $\mathrm{TiCl}_{4}$.

Table S2. Results of ROMP of BT- $\boldsymbol{d}$ and BT- $\boldsymbol{t}$ toward P3

\begin{tabular}{ccrrcrcrc}
\hline Entry & Monomer & $\begin{array}{c}\text { Temp. } \\
\left({ }^{\circ} \mathrm{C}\right)\end{array}$ & $\begin{array}{c}\text { Time } \\
(\mathrm{min})\end{array}$ & Solvent & Catalyst ${ }^{[\mathrm{a}]}$ & $M_{\mathrm{n}}{ }^{\mathrm{bb}]}$ & $M_{\mathrm{n}}{ }^{[\mathrm{c}]}$ & $M_{\mathrm{w}} / M_{\mathrm{n}}{ }^{[\mathrm{c}]}$ \\
\hline $\mathbf{1}$ & BT- $\boldsymbol{d}$ & 120 & 6 & $p$-xlyene & $2^{\text {nd }}$ & 8600 & 8600 & 1.9 \\
$\mathbf{2}$ & BT- $\boldsymbol{d}$ & 95 & 60 & 1.4 -dioxane & $3^{\text {rd }}$ & 8600 & 510 & 2.2 \\
$\mathbf{3}$ & BT- $\boldsymbol{t}$ & 120 & 6 & $p$-xlyene & $2^{\text {nd }}$ & 12910 & 12400 & 2.0 \\
$\mathbf{4}$ & BT- $\boldsymbol{t}$ & 120 & 6 & $p$-xlyene & $3^{\text {rd }}$ & 12910 & 6800 & 1.2 \\
$\mathbf{5}$ & BT- $\boldsymbol{t}$ & 120 & 60 & $p$-xlyene & $3^{\text {rd }}$ & 12910 & 17400 & 2.1 \\
$\mathbf{6}$ & BT- $\boldsymbol{t}$ & 95 & 60 & 1.4 -dioxane & $3^{\text {rd }}$ & 12910 & 6700 & 1.7 \\
\hline
\end{tabular}

[a] Second- or third generation Grubbs catalyst. [b] Expected $M_{\mathrm{n}}$. [c] determined by GPC (THF eluent and polystyrene standards). 


\section{NMR and mass spectra}

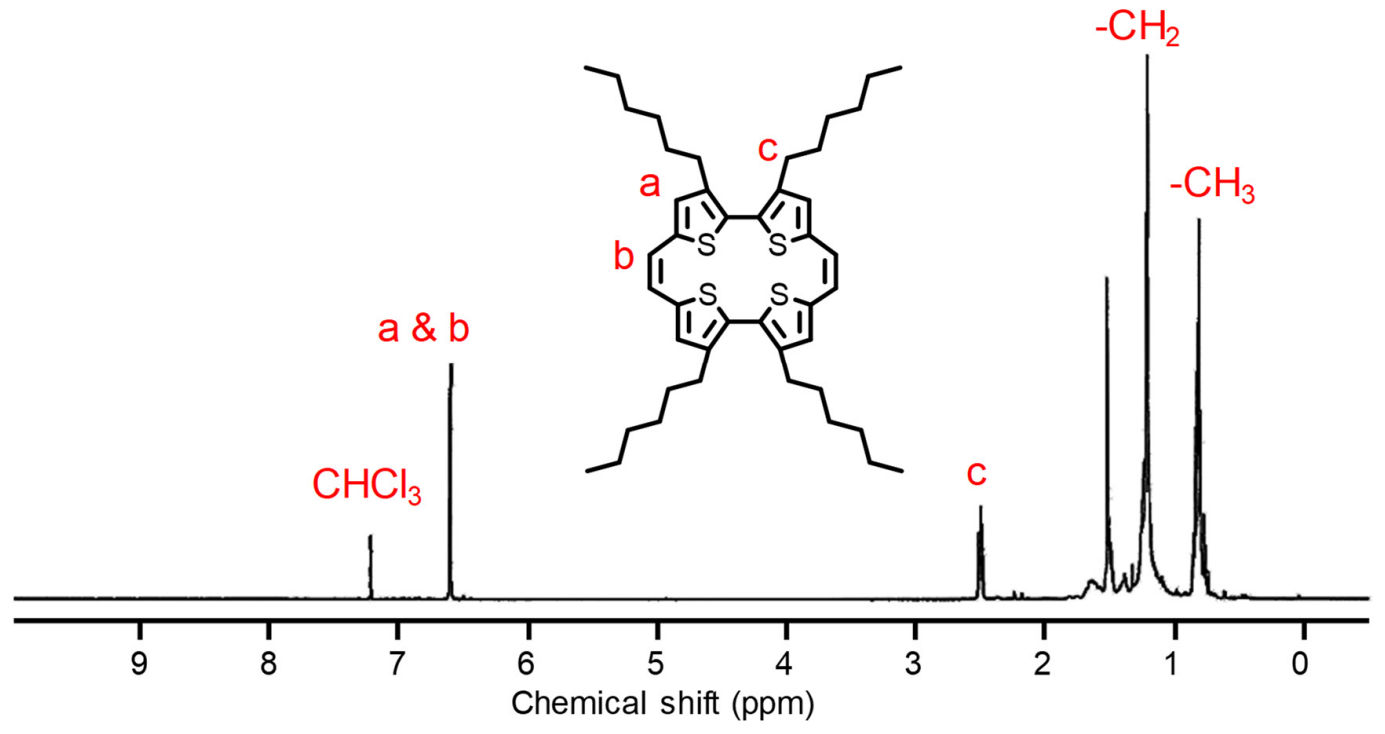

Figure S1. ${ }^{1} \mathrm{H}$ NMR spectrum $\left(500 \mathrm{MHz}, \mathrm{CDCl}_{3}\right)$ of BT-d.

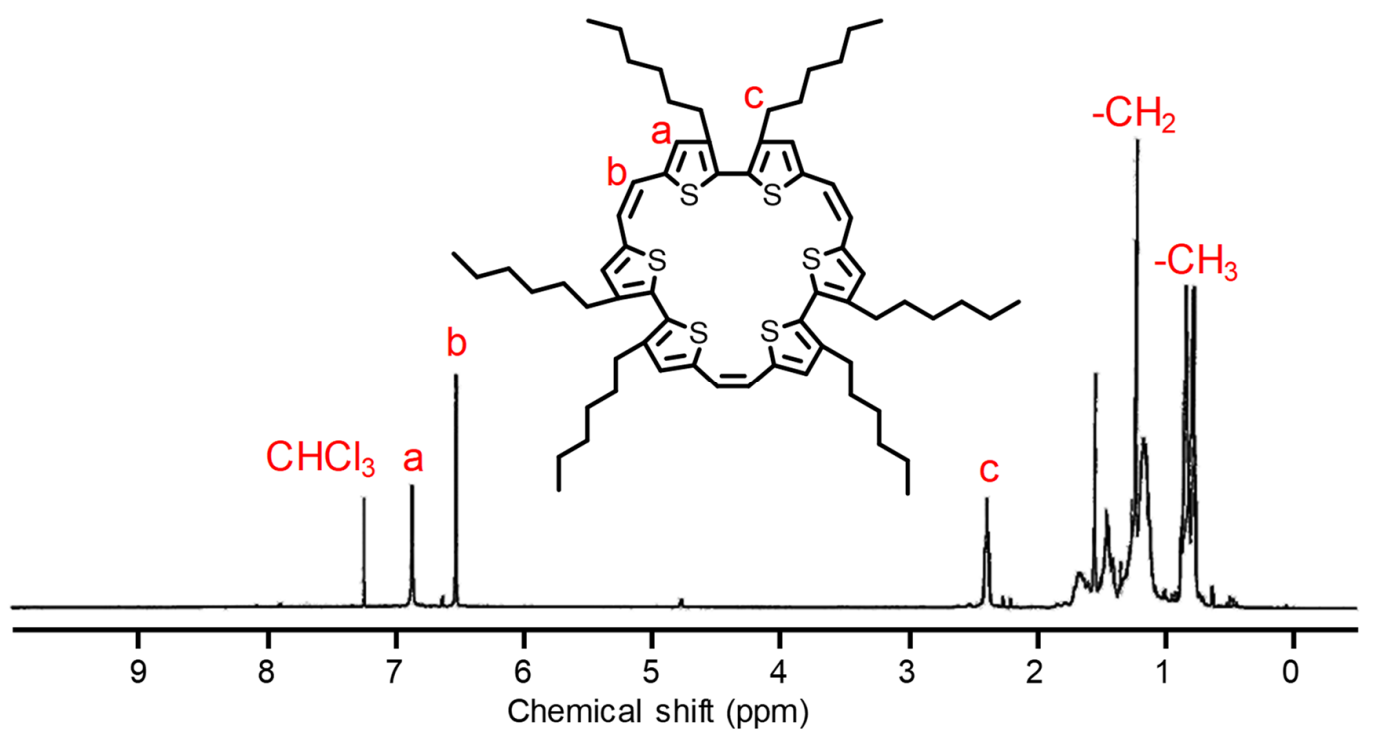

Figure S2. ${ }^{1} \mathrm{H}$ NMR spectrum $\left(500 \mathrm{MHz}, \mathrm{CDCl}_{3}\right)$ of BT-t. 


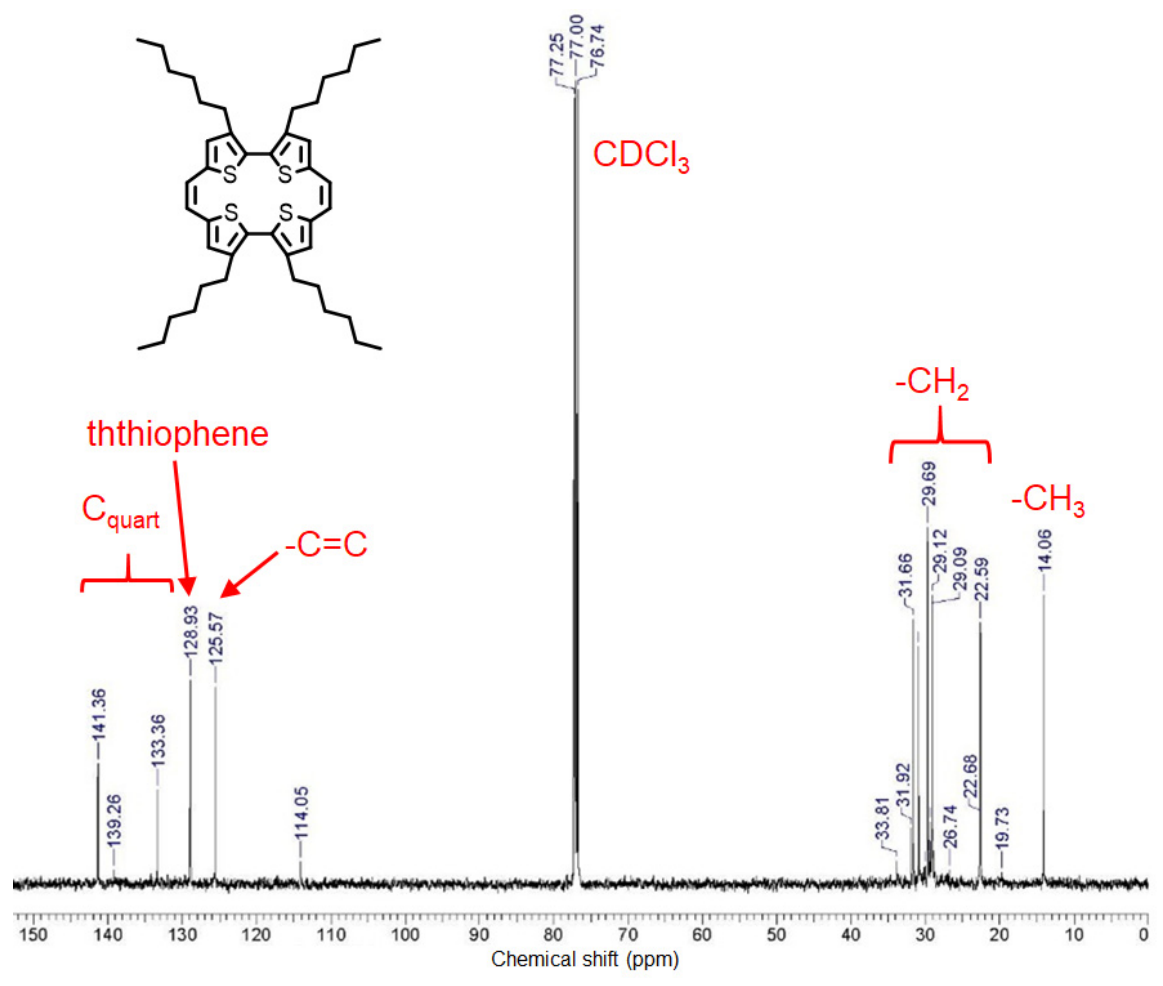

Figure S3. ${ }^{13} \mathrm{C}$ NMR spectrum $\left(125 \mathrm{MHz}, \mathrm{CDCl}_{3}\right)$ of BT- $\boldsymbol{d}$.

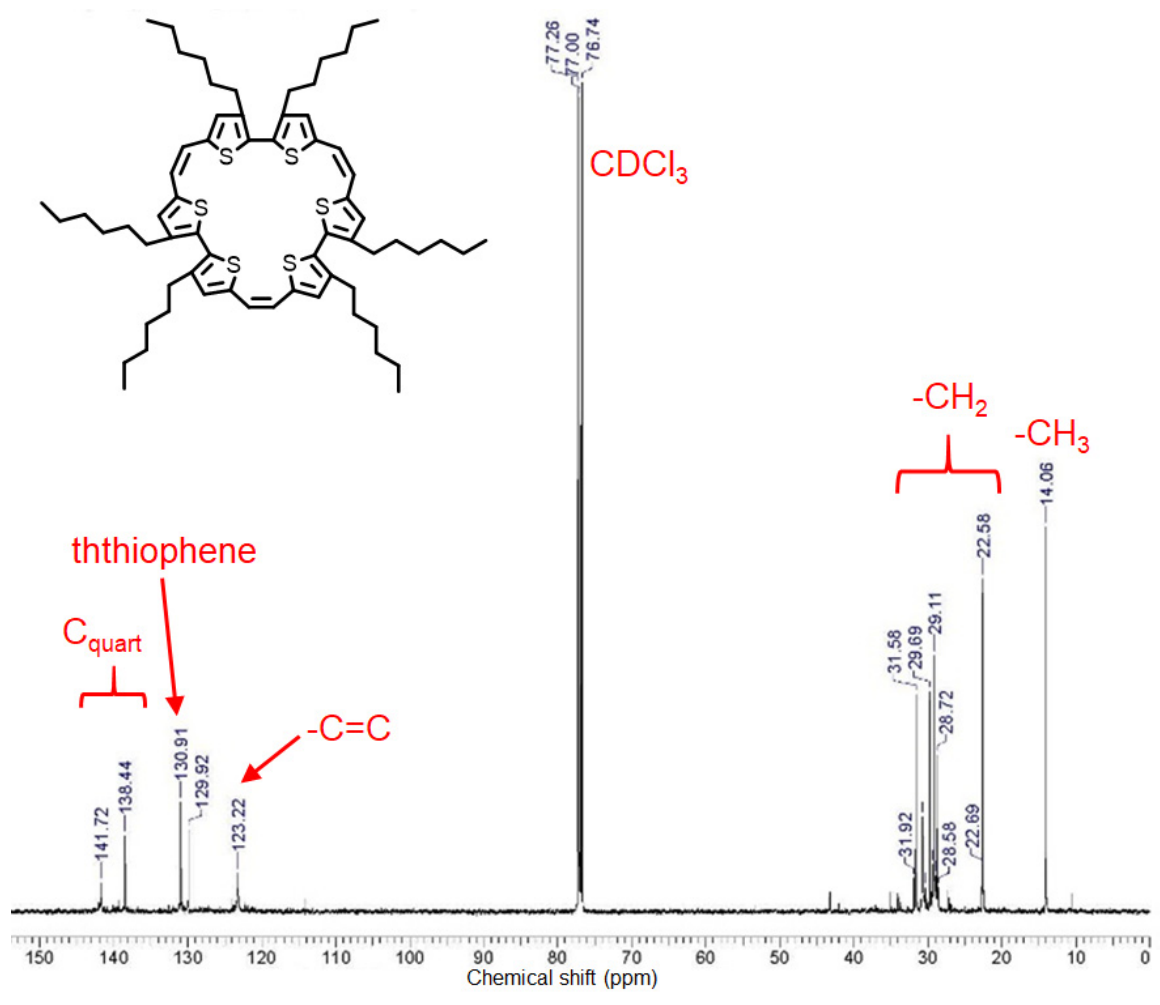

Figure S4. ${ }^{13} \mathrm{C}$ NMR spectrum $\left(125 \mathrm{MHz}, \mathrm{CDCl}_{3}\right)$ of BT-t. 


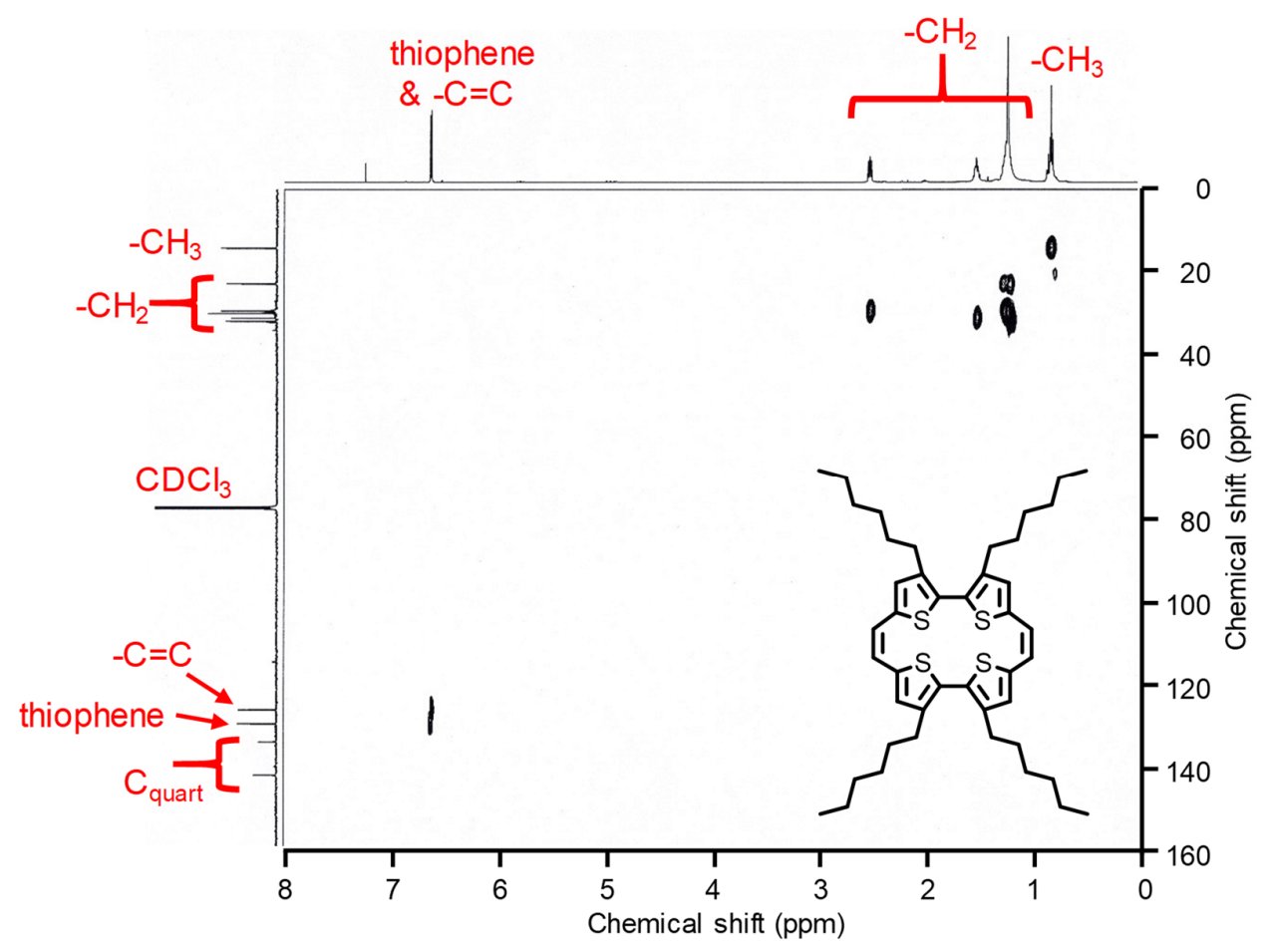

Figure S5. HSQC NMR spectrum (500 MHz \& $\left.125 \mathrm{MHz}, \mathrm{CDCl}_{3}\right)$ of BT-d.

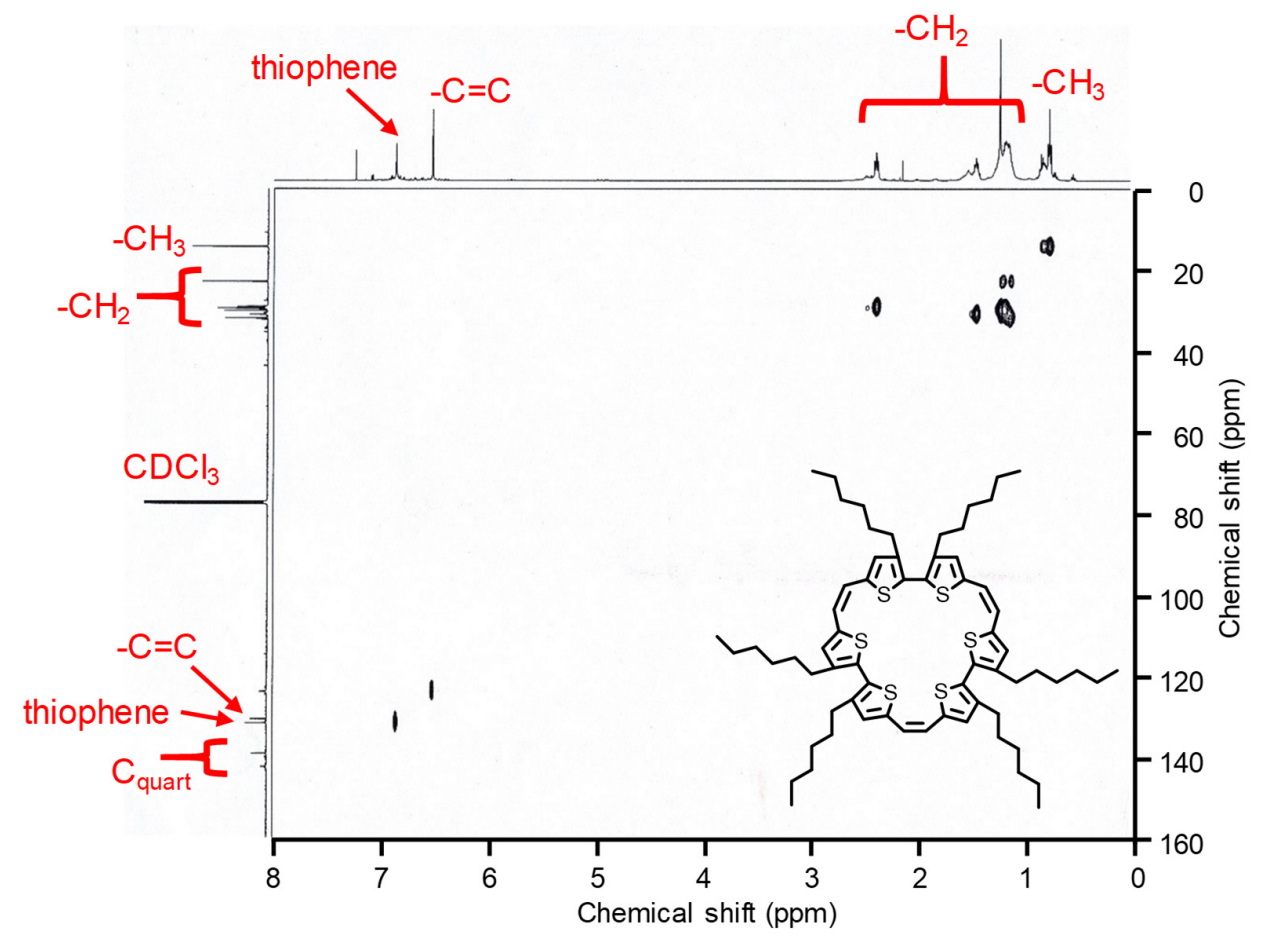

Figure S6. HSQC NMR spectrum (500 MHz \& $\left.125 \mathrm{MHz}, \mathrm{CDCl}_{3}\right)$ of BT-t. 


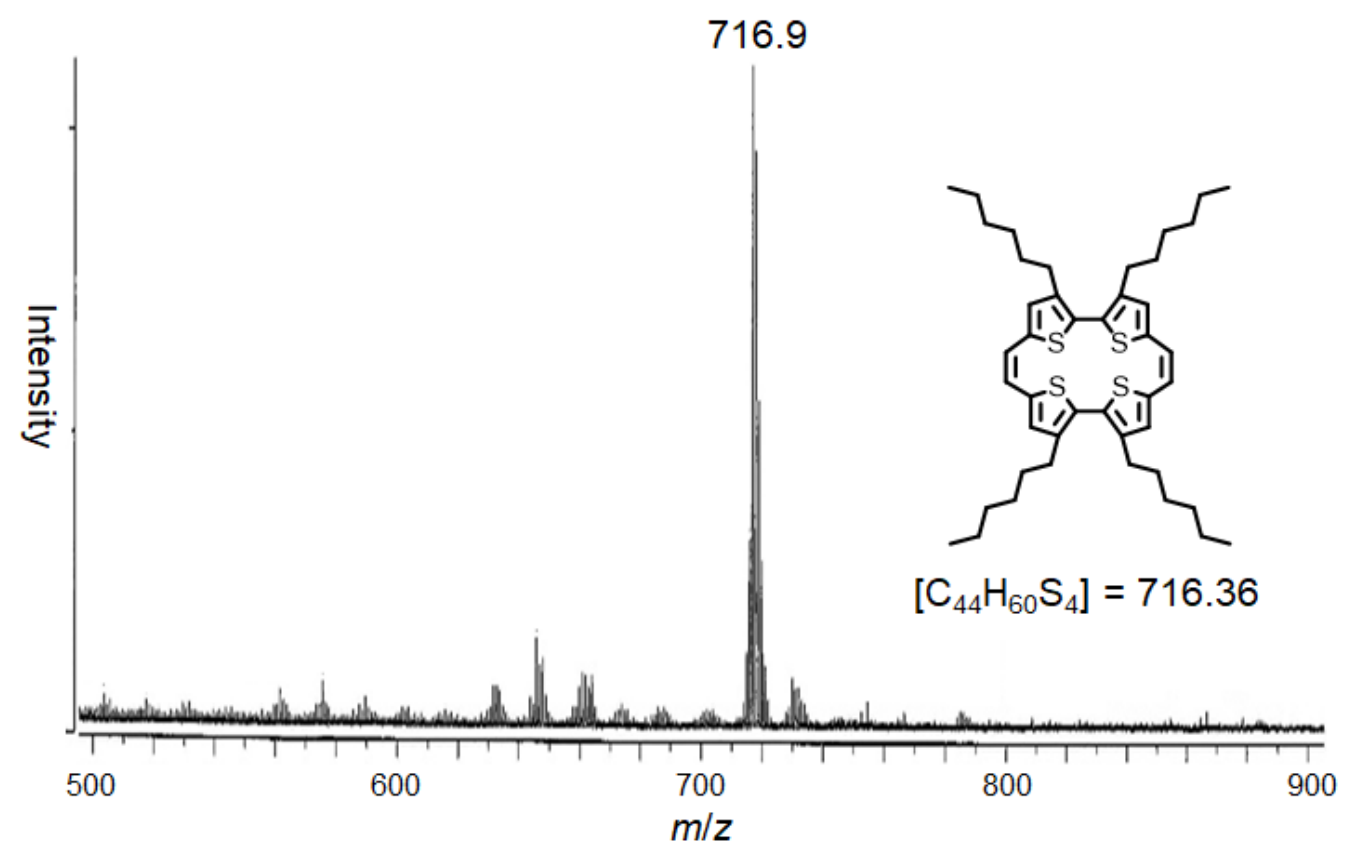

Figure S7. FAB mass spectrum of BT- $\boldsymbol{d}$.

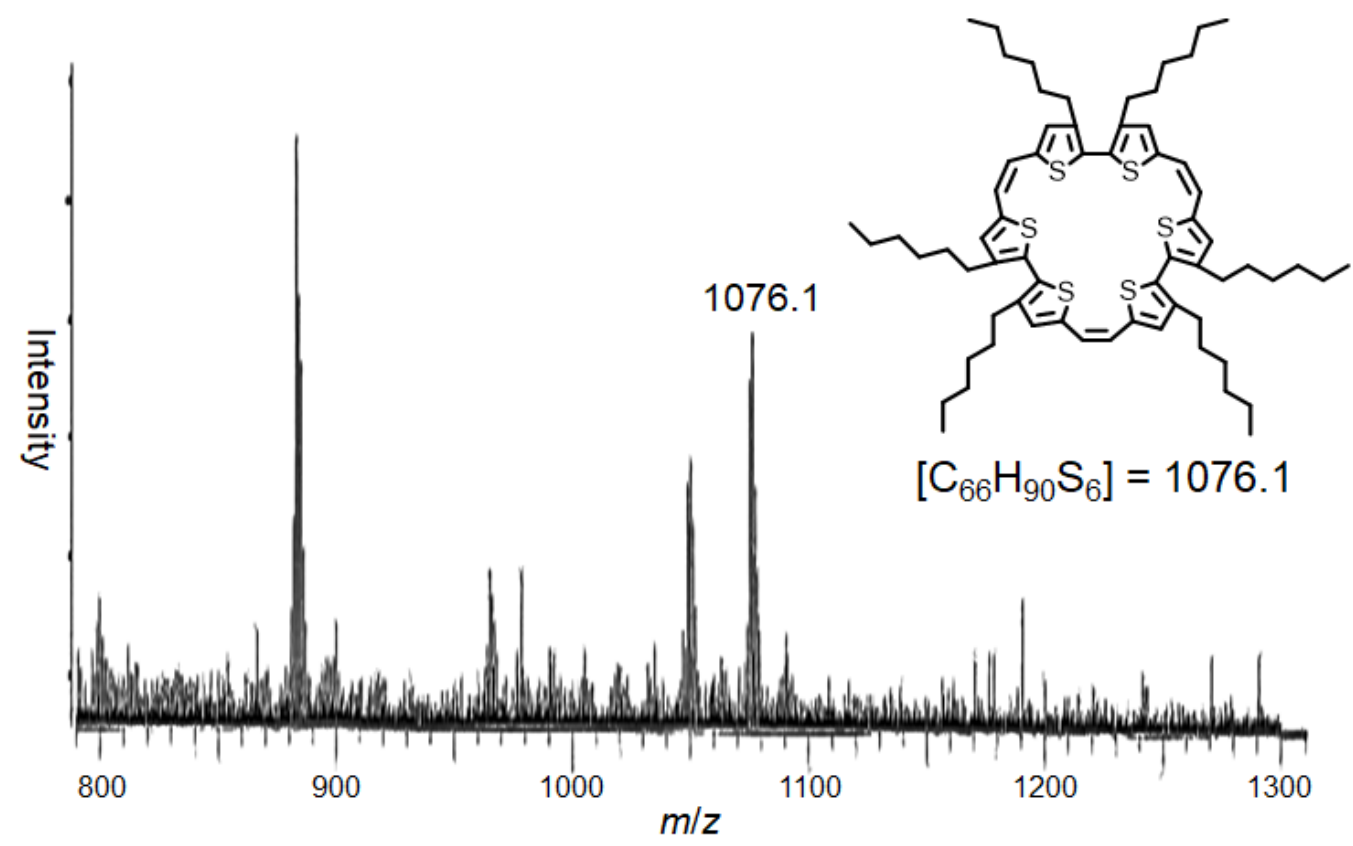

Figure S8. FAB mass spectrum of BT- $\boldsymbol{t}$. 
The ${ }^{1} \mathrm{H}$ NMR spectrum of $\mathbf{P} 3$ showed peaks at 6.92 and 6.89 representing the protons on the thiophene and vinylene groups (Figure S9). In the ${ }^{1} \mathrm{H}$ NMR spectrum, peaks corresponding to the cis-form of vinylene were not observed. This is probably due to thermal isomerization from the cis to trans form during polymerization or the quenching process.

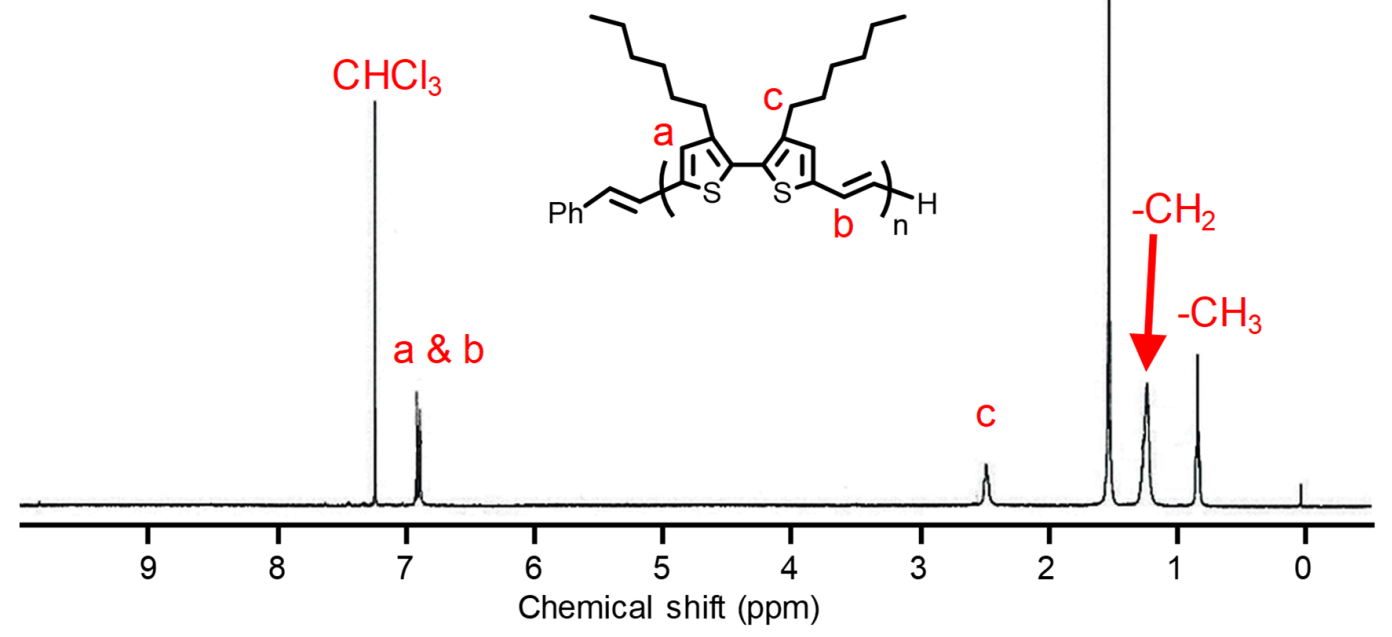

Figure S9. ${ }^{1} \mathrm{H}$ NMR spectrum $\left(500 \mathrm{MHz}, \mathrm{CDCl}_{3}\right)$ of $\mathbf{P 3}$ (from BT-d).

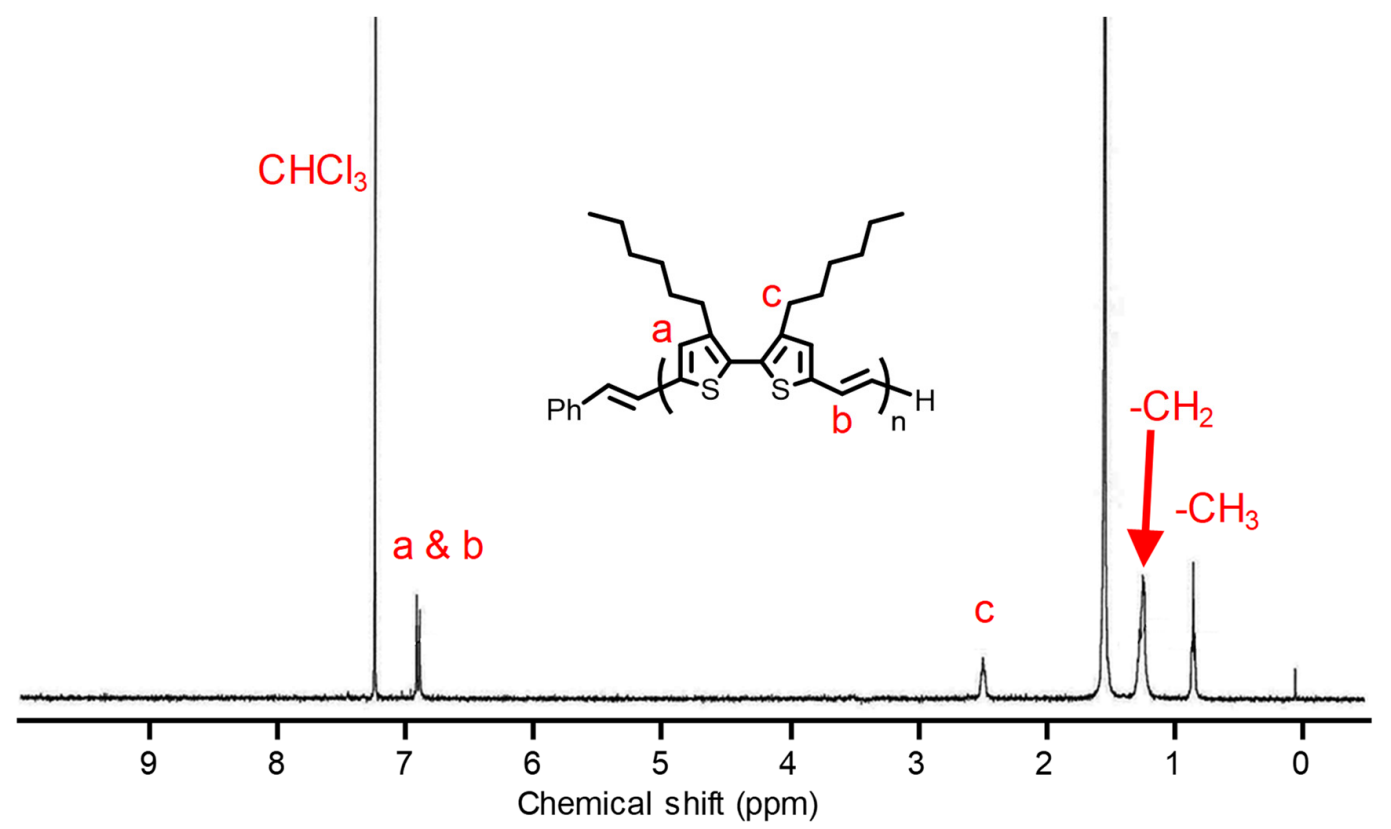

Figure S10. ' $\mathrm{H}$ NMR spectrum (500 MHz, $\left.\mathrm{CDCl}_{3}\right)$ of P3' (from BT-t). 

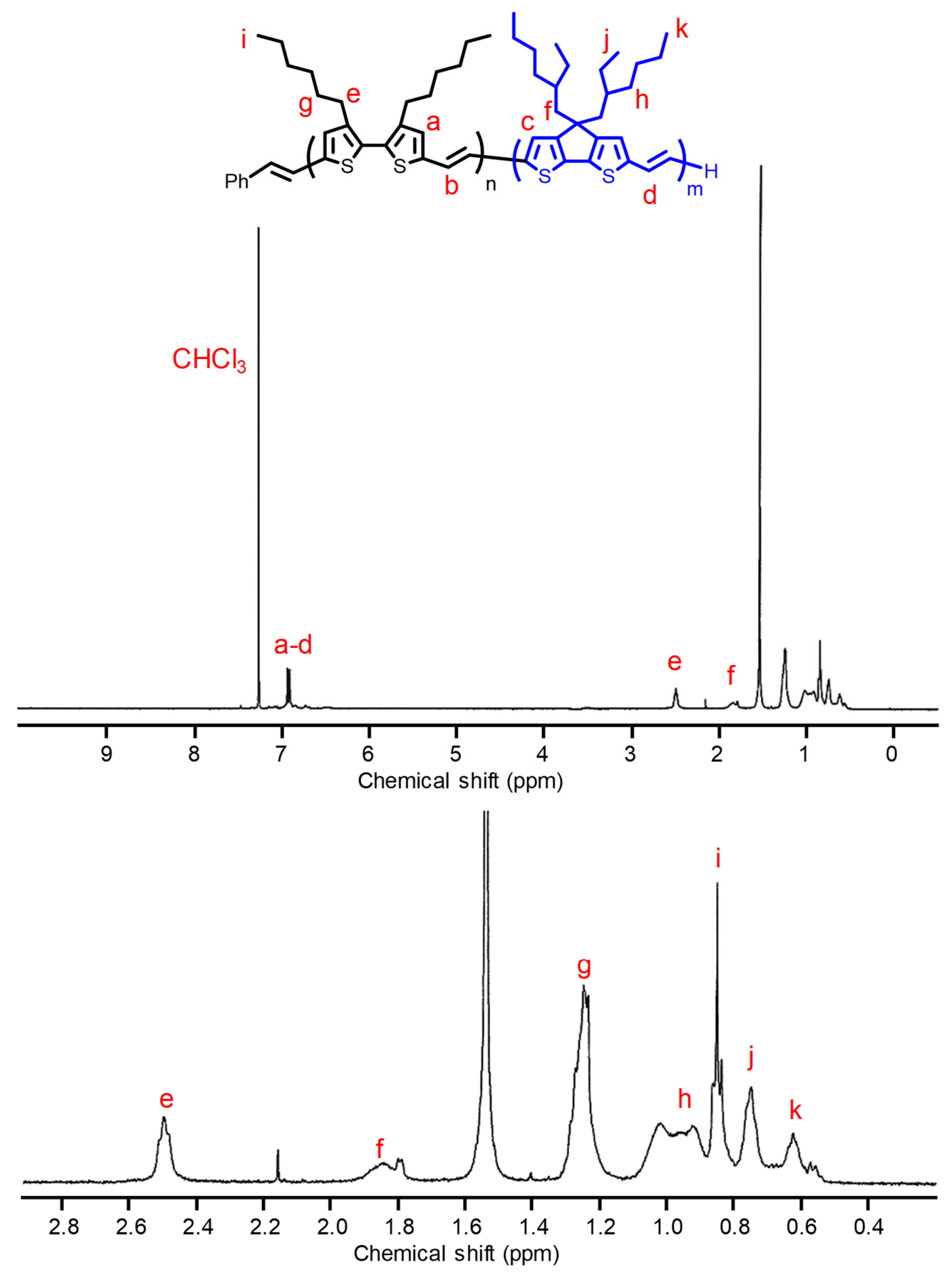

Figure S11. ${ }^{1} \mathrm{H}$ NMR spectra $\left(500 \mathrm{MHz}, \mathrm{CDCl}_{3}\right)$ of P5a. 

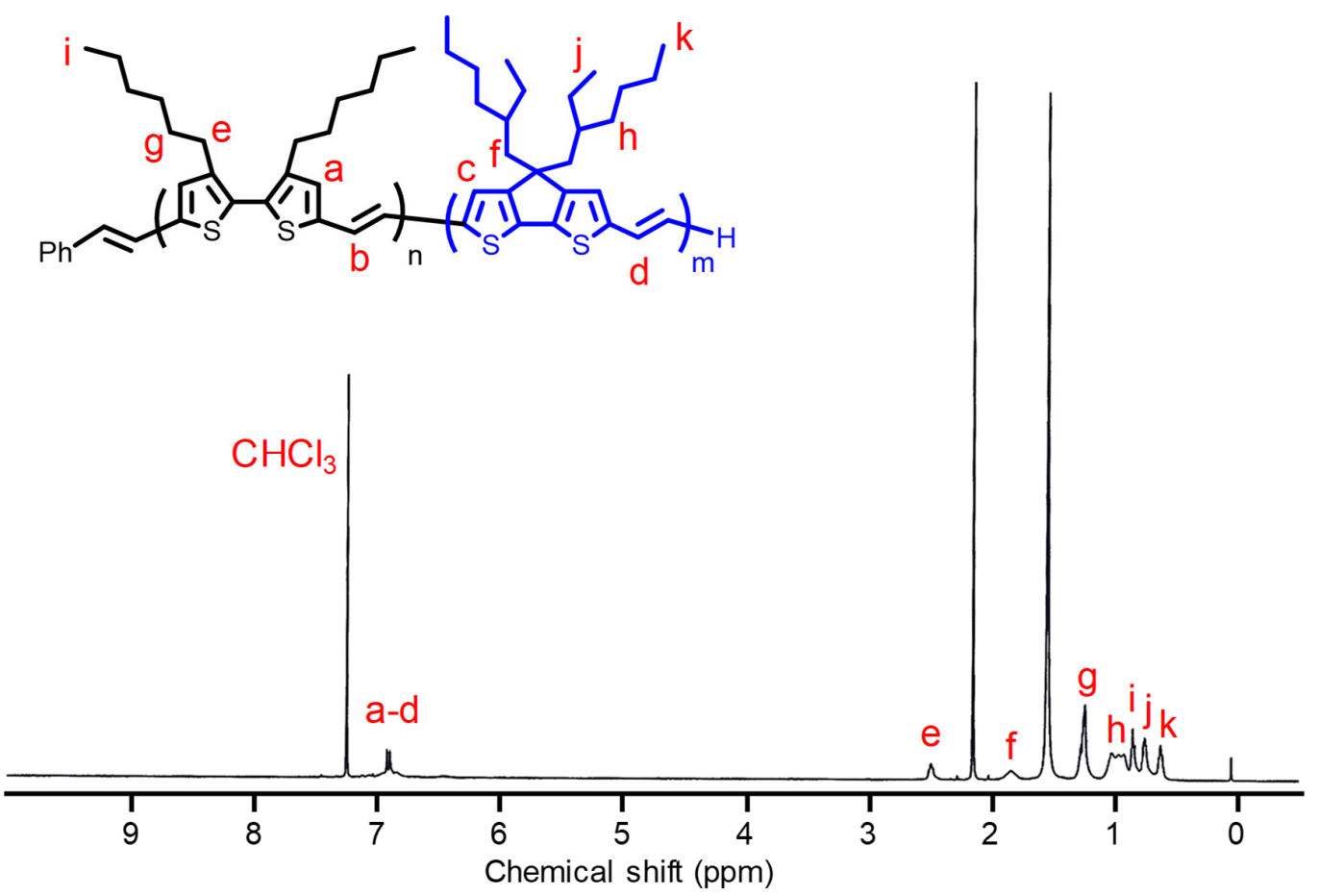

Figure S12. ${ }^{1} \mathrm{H}$ NMR spectrum $\left(500 \mathrm{MHz}, \mathrm{CDCl}_{3}\right)$ of $\mathbf{P 5 b}$.

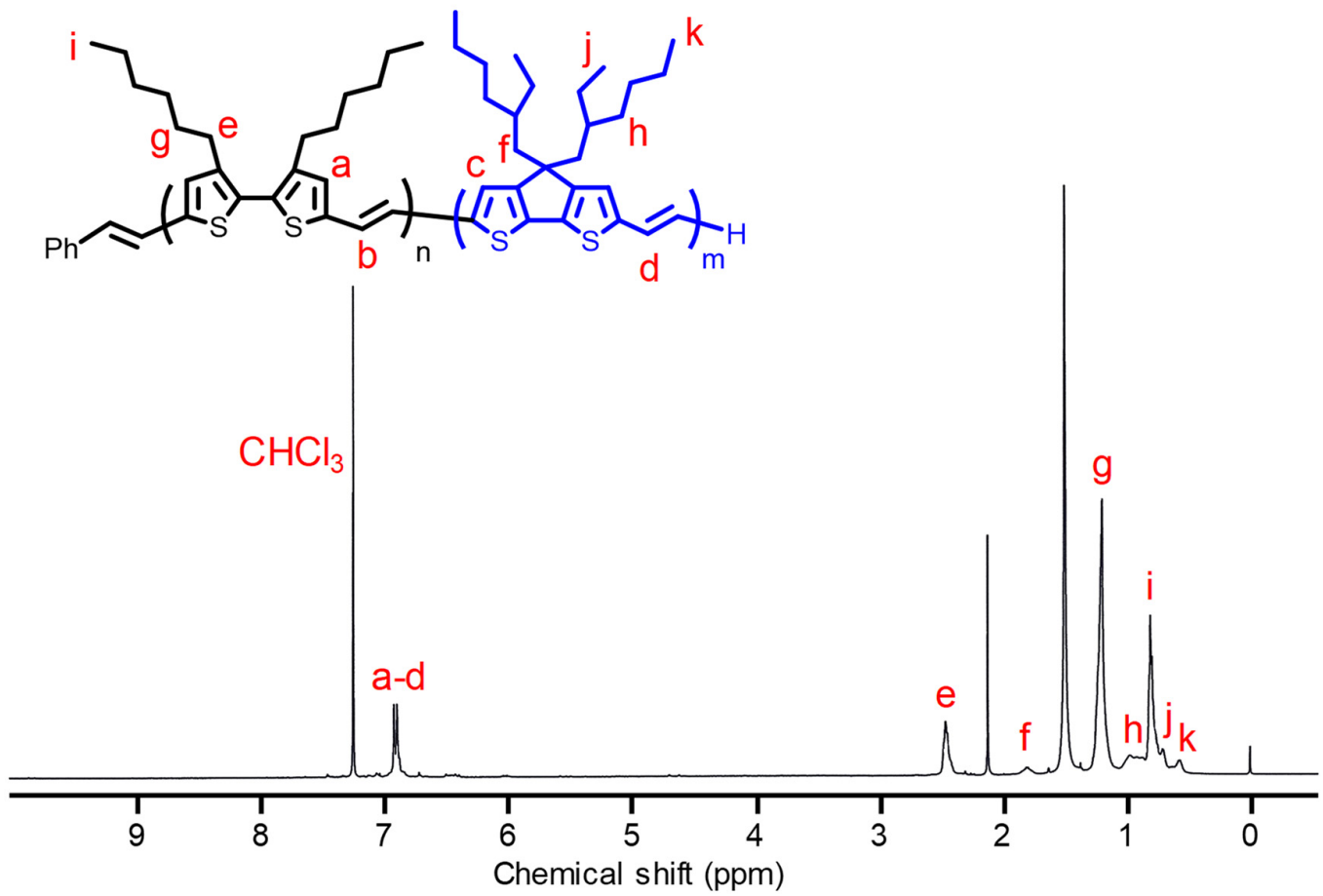

Figure S13. ${ }^{1} \mathrm{H}$ NMR spectrum $\left(500 \mathrm{MHz}, \mathrm{CDCl}_{3}\right)$ of $\mathbf{P 5 c}$. 


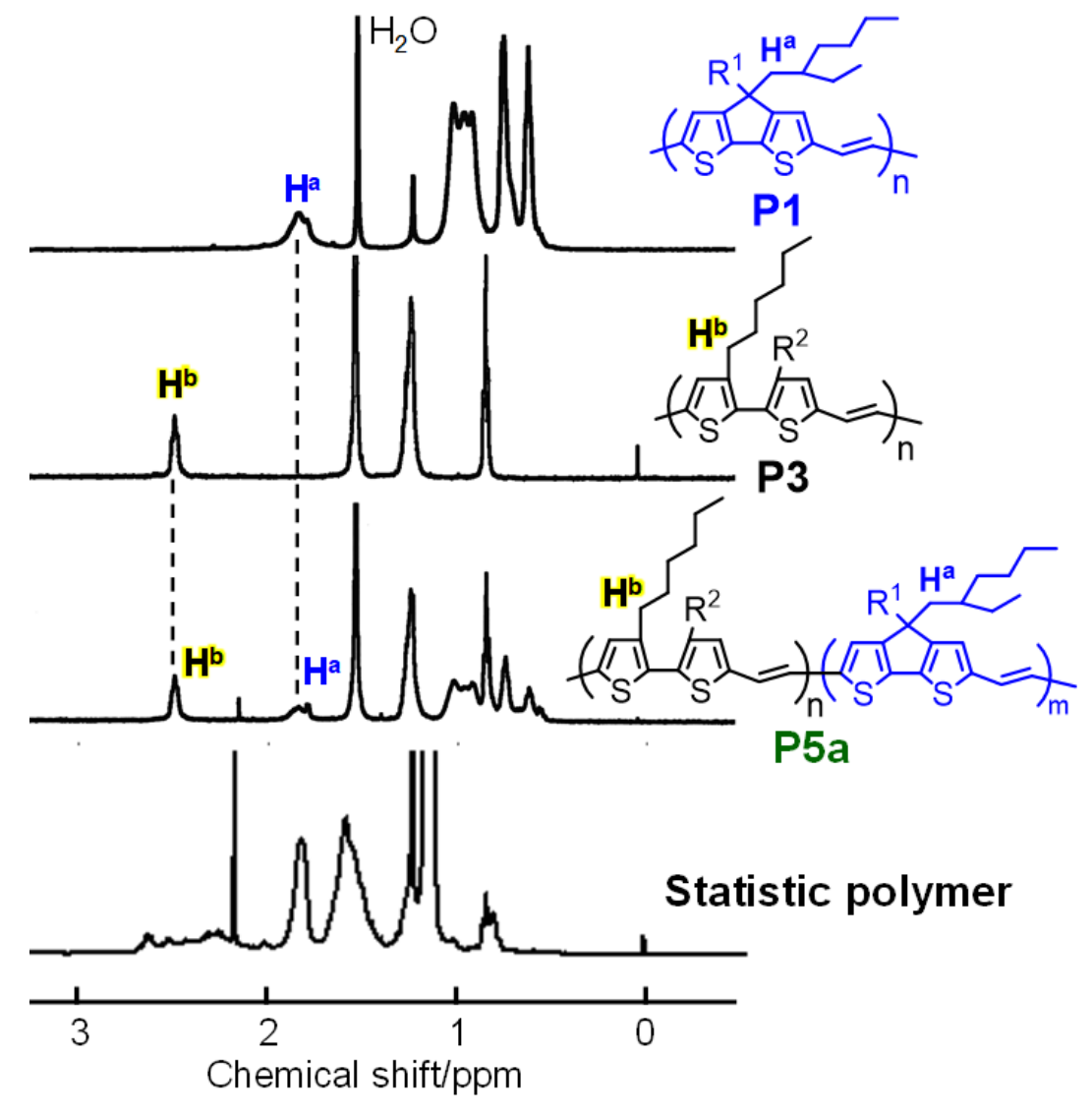

Figure S14. ${ }^{1} \mathrm{H}$ NMR spectrua $\left(500 \mathrm{MHz}, \mathrm{CDCl}_{3}\right)$ of P1, P3, P5a, and a statistic copolymer obtained from BT- $d$ and CPDT- $t$. 

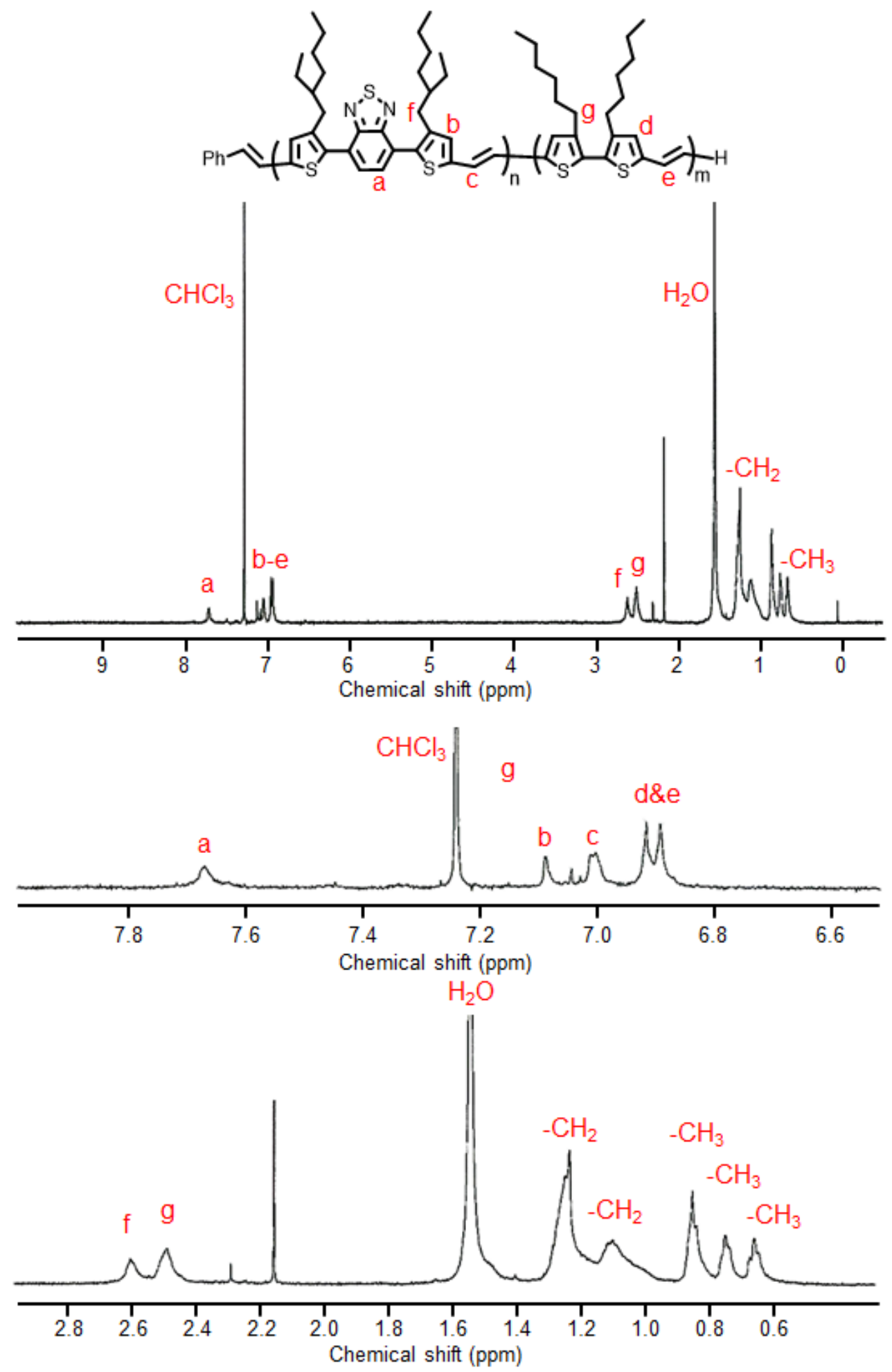

Figure S15. ${ }^{1} \mathrm{H}$ NMR spectra $\left(500 \mathrm{MHz}, \mathrm{CDCl}_{3}\right)$ of P6a. 


\section{GPC elution curves}

Figure S16 compares the GPC elution curves for P5a and ROMP of BT- $d$ under similar conditions as the first ROMP for P5a. The GPC elution curve shifted from a lower molecular weight region to a higher region.

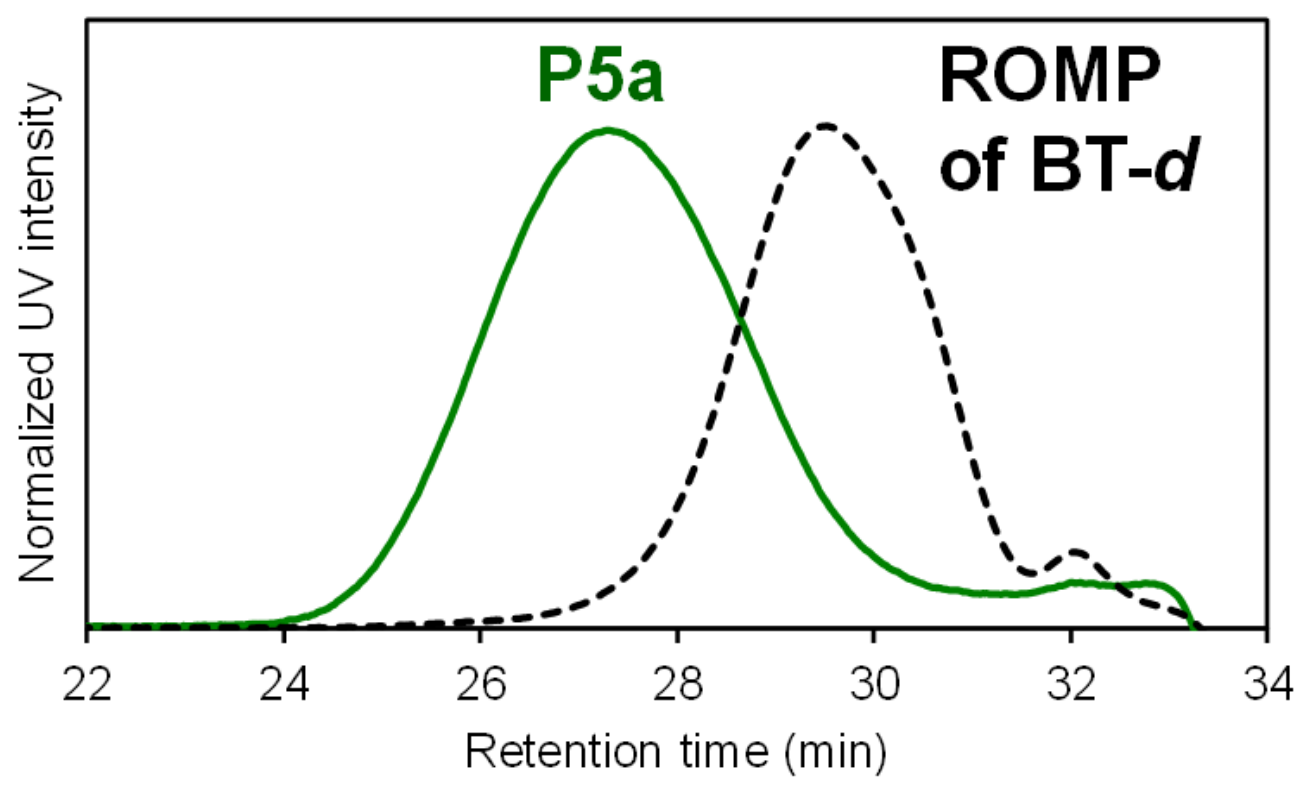

Figure S16. GPC elution curves of P5a and ROMP of BT- $d$ detected using a UV-Vis detector at $254 \mathrm{~nm}$ (THF eluent, flow rate $\left.=1.0 \mathrm{~mL} \mathrm{~min}^{-1}\right)$. 


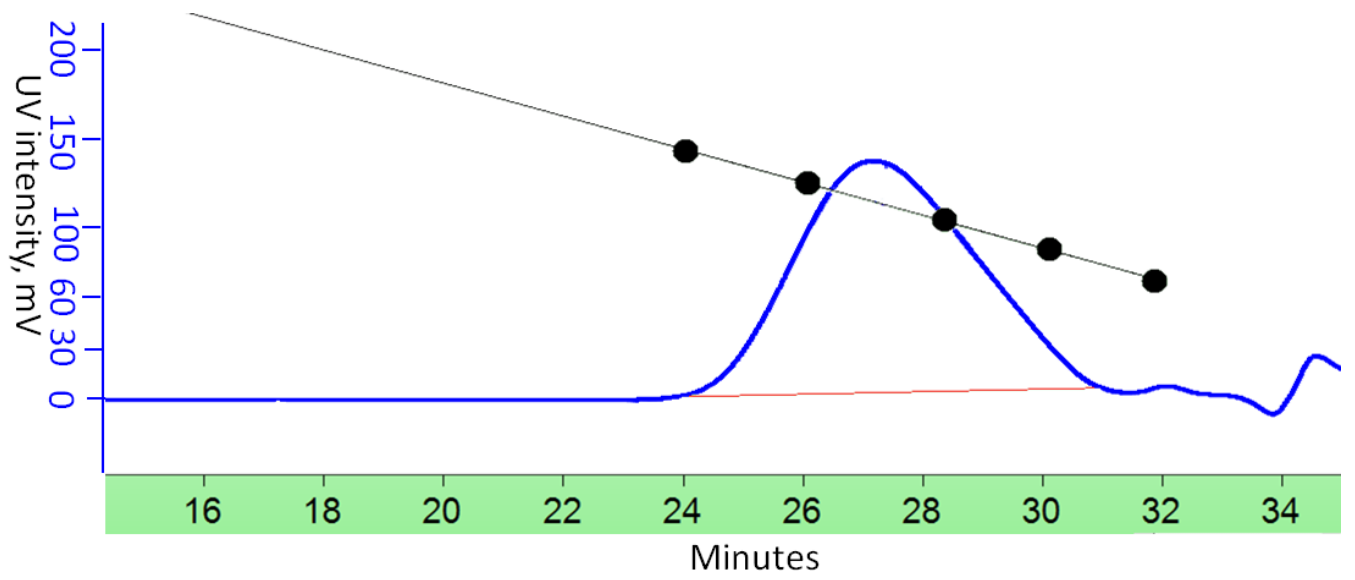

Figure S17. GPC elution curve of P3 (from BT-d).

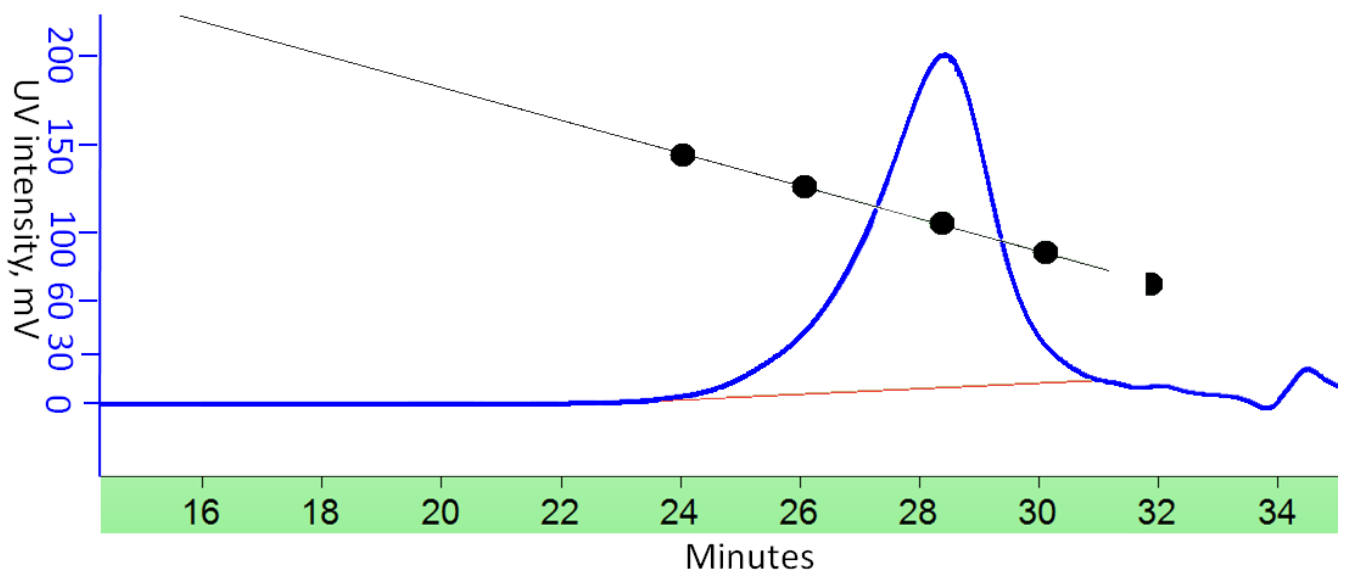

Figure S18. GPC elution curve of P3' (from BT-t). 


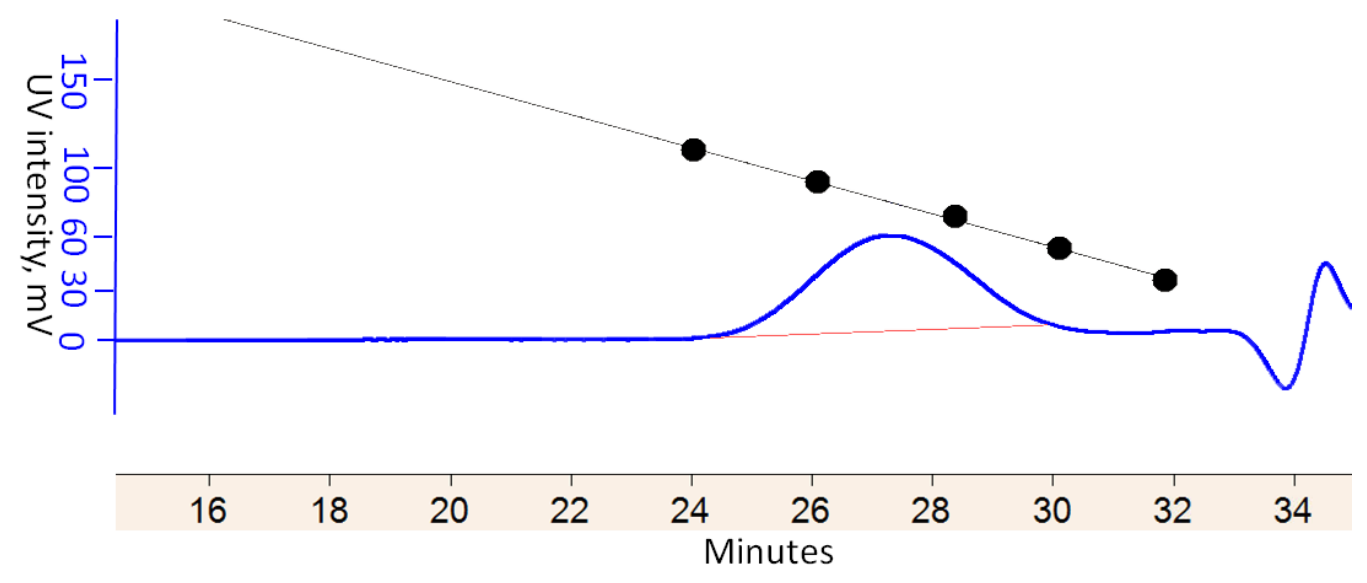

Figure S19. GPC elution curve of P5a.

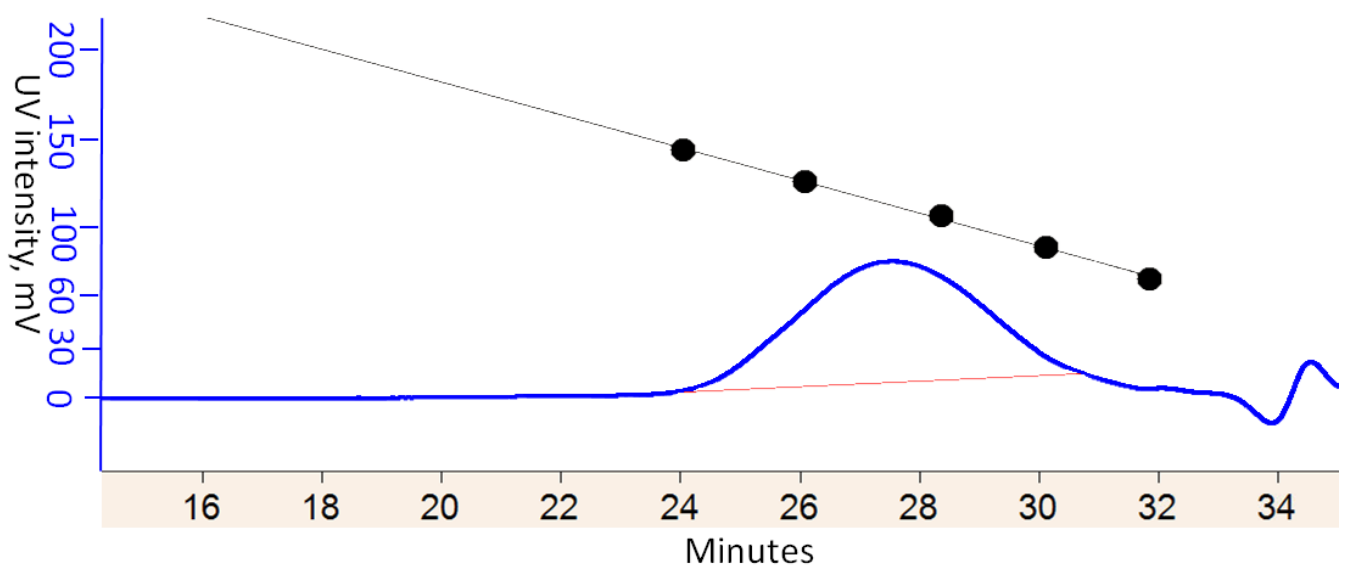

Figure S20. GPC elution curve of P6a. 


\section{Optical and electrochemical properties}

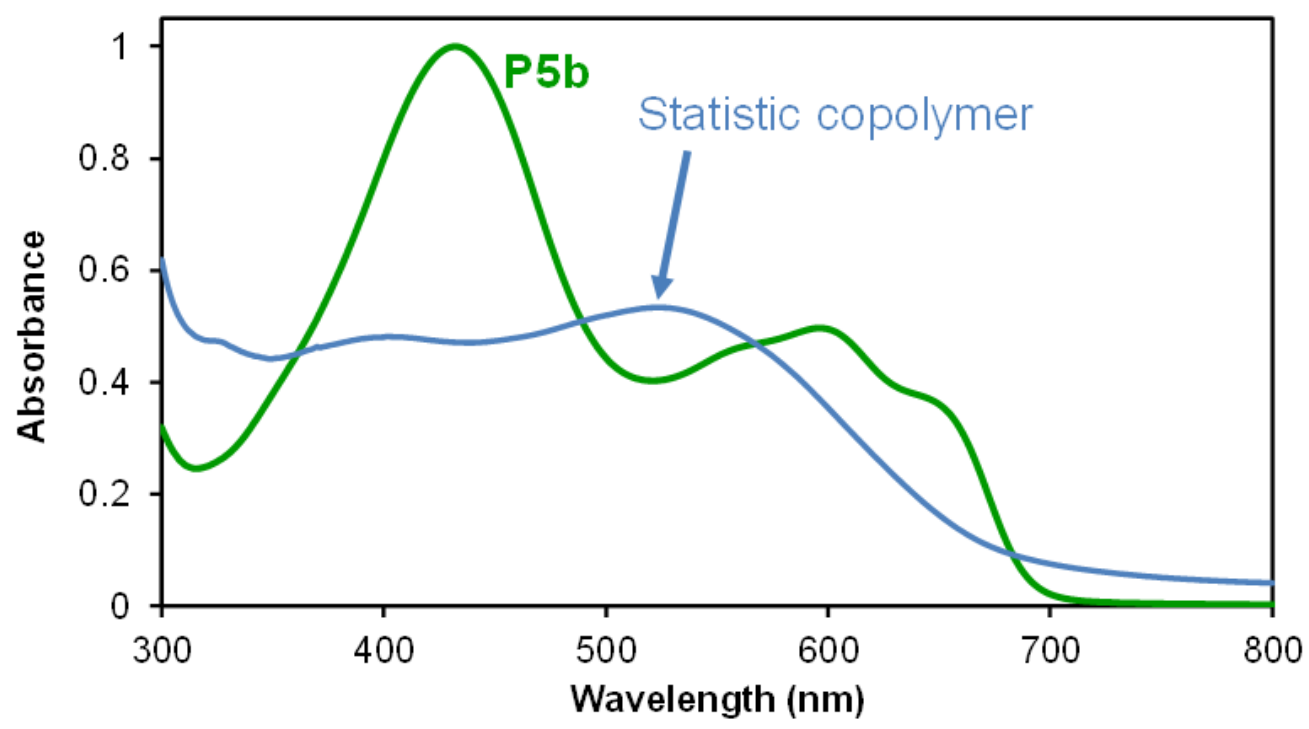

Figure S21. UV-vis spectra of P5b and statistic copolymer obtained from BT- $d$ and CPDT- $t$.

Table S3. Summary of optical properties of polymers.

\begin{tabular}{|c|c|c|c|c|c|c|}
\hline \multirow{2}{*}{ Polymer } & \multicolumn{2}{|c|}{$\lambda_{\max }(\mathrm{nm})$} & \multicolumn{2}{|c|}{$\lambda_{\text {onset }}(\mathrm{nm})$} & \multirow{2}{*}{$\begin{array}{c}\Delta \lambda \\
(\mathrm{nm})^{[\mathrm{a}]}\end{array}$} & \multirow{2}{*}{$\begin{array}{r}E_{\mathrm{g}}(\mathrm{eV}) \\
\text { in Film } \\
{[\mathrm{b}}\end{array}$} \\
\hline & Solution & Film & Solution & Film & & \\
\hline P1 & $665 / 608$ & 611 & 724 & 740 & 54 & 1.68 \\
\hline $\mathbf{P 2}$ & $493 / 376$ & $501 / 378$ & 625 & 636 & $8 / 2$ & 1.95 \\
\hline P3 & 423 & 401 & 534 & 559 & 22 & 2.22 \\
\hline $\mathbf{P 4}$ & $650 / 604 / 526 / 382$ & $535 / 384$ & 724 & 738 & $9 / 2$ & 1.68 \\
\hline P5b & $597 / 433$ & $598 / 434$ & 709 & 719 & $1 / 1$ & 1.73 \\
\hline P5a & 395 & 401 & 650 & 664 & 6 & 1.87 \\
\hline
\end{tabular}

[a] Difference of $\lambda_{\max }$ between solution and film. [b] $E_{\mathrm{g}}=$ optical band gap in the film. 

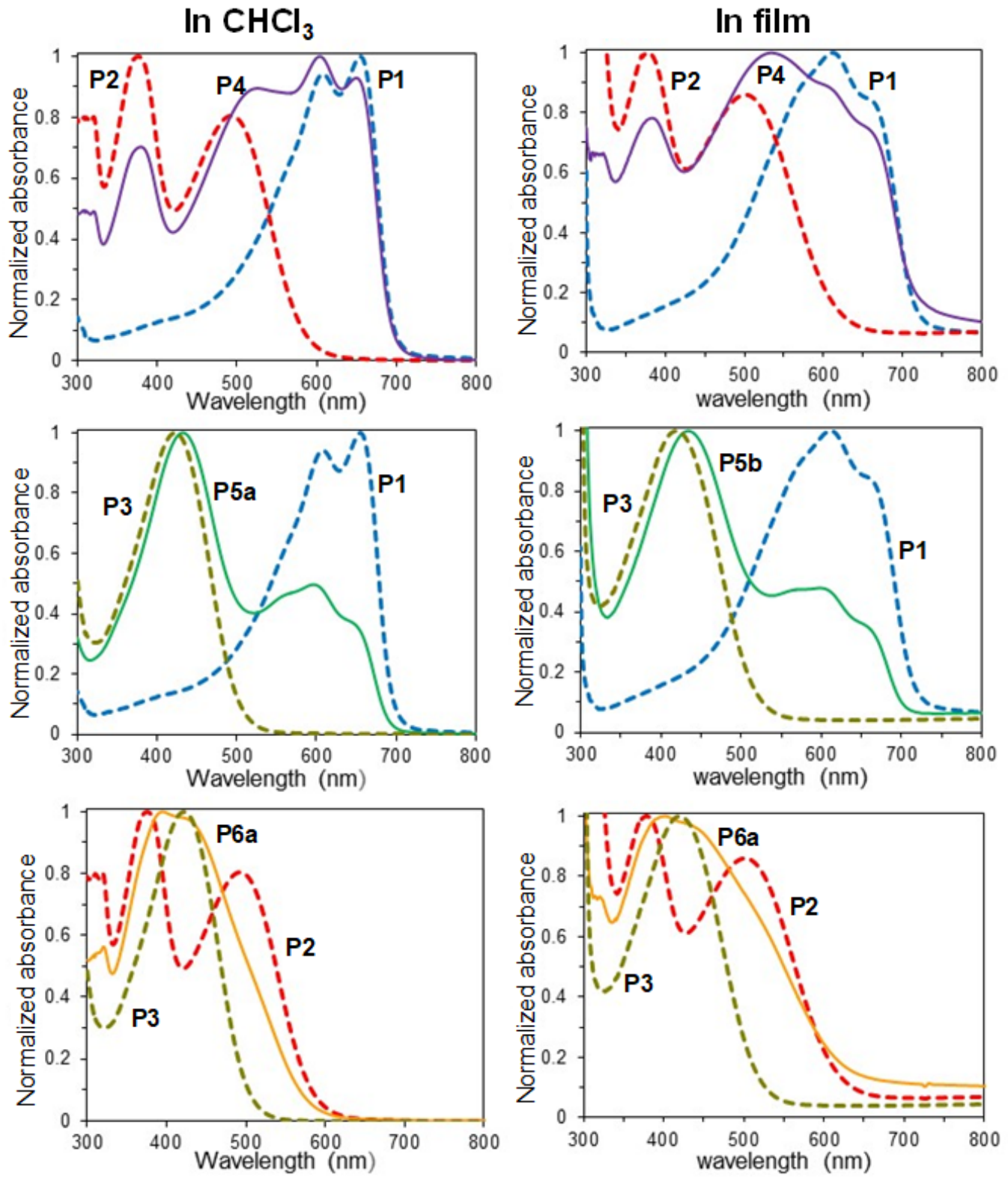

Figure S22. UV-vis spectra of polymers in $\mathrm{CHCl}_{3}$ and film. 
The electrochemical properties of the polymers were investigated by cyclic voltammetry, as shown in Figure S23. The cyclic voltammogram (CV) of P5b shows an anodic shoulder around $1.31 \mathrm{~V}$ (vs $\mathrm{AgCl} / \mathrm{Ag}$ ), a peak at $1.66 \mathrm{~V}$ and a cathodic shoulder around $-0.85 \mathrm{~V}$. Among them, two anodic signals imply the presence of CPDT-vinylene and BT-vinylene units. These responses were consistent with those observed in CVs of their homopolymers. The CV of P6a also shows the superposition of two compositions, DTBT-vinylene and BT-vinylene units.

The HOMO level of the polymers was estimated from the onset of the oxidation signal in the CVs. Optical bandgap $\left(E_{\mathrm{g}}\right)$, obtained from an onset of the UV-Vis spectra of the polymers, was added to the HOMO to obtain the LUMO. The HOMO and LUMO levels were calculated to be -4.95 and $-3.27 \mathrm{eV}\left(E_{\mathrm{g}}=1.68 \mathrm{eV}\right)$ for $\mathbf{P 4},-4.95$ and -3.22 $\mathrm{eV}\left(E_{\mathrm{g}}=1.73 \mathrm{eV}\right)$ for P5b and -5.24 and $-3.36 \mathrm{eV}\left(E_{\mathrm{g}}=1.87 \mathrm{eV}\right)$ for P6a (Table S4 and Figure S24). As the copolymers exhibit superimposed CVs from their two compositions, the HOMO and LUMO levels of these two polymers tend to show similar values to one of their units. P4 and P5b show higher HOMO levels than P6a around $5.0 \mathrm{eV}$, suggesting that CPDT-vinylene contributes in increasing HOMO because of the electron-donating property and planar structure of the CPDT group. By contrast, P4 and P6a tend to exhibit lower LUMO levels than P5b in the range between -3.3 and -3.4 $\mathrm{eV}$, implying that the DTBT-vinylene decreases LUMO because of the stronger electron-accepting property of the DTBT group.

Table S4. Summary of electrochemical properties of polymers.

\begin{tabular}{cccc}
\hline Polymer & HOMO $(\mathrm{eV})^{[\mathrm{a}]}$ & $\mathrm{LUMO}(\mathrm{eV})^{[\mathrm{b}]}$ & $E_{\mathrm{g}-\mathrm{ec}}(\mathrm{eV})^{[\mathrm{c}]}$ \\
\hline P1 & -4.81 & -3.13 & 1.68 \\
P2 & -5.49 & -3.54 & 1.95 \\
P3 & -5.24 & -3.00 & 2.24 \\
P4 & -4.95 & -3.27 & 1.68 \\
P5b & -5.24 & -3.22 & 2.02 \\
P6a & -4.95 & -3.36 & 1.59 \\
\hline
\end{tabular}

[a] $\mathrm{HOMO}=-\left(4.8+E_{\mathrm{pa}-\text { onset }}-E_{\mathrm{Fc}}\right)$. Half wave potential of ferrocene, $E_{\mathrm{Fc}}$ was measured in $\mathrm{CH}_{3} \mathrm{CN}$ solution. $\left(E_{\mathrm{Fc}}=0.94 \mathrm{~V}\right)$. [b] LUMO $=-\left(4.8+E_{\mathrm{pa}-\text { onset }}-E_{\mathrm{Fc}}\right)$. [c] Electrochemical band gap was calculated from $E_{\mathrm{Fc}}=\mathrm{LUMO}-\mathrm{HOMO}$. 

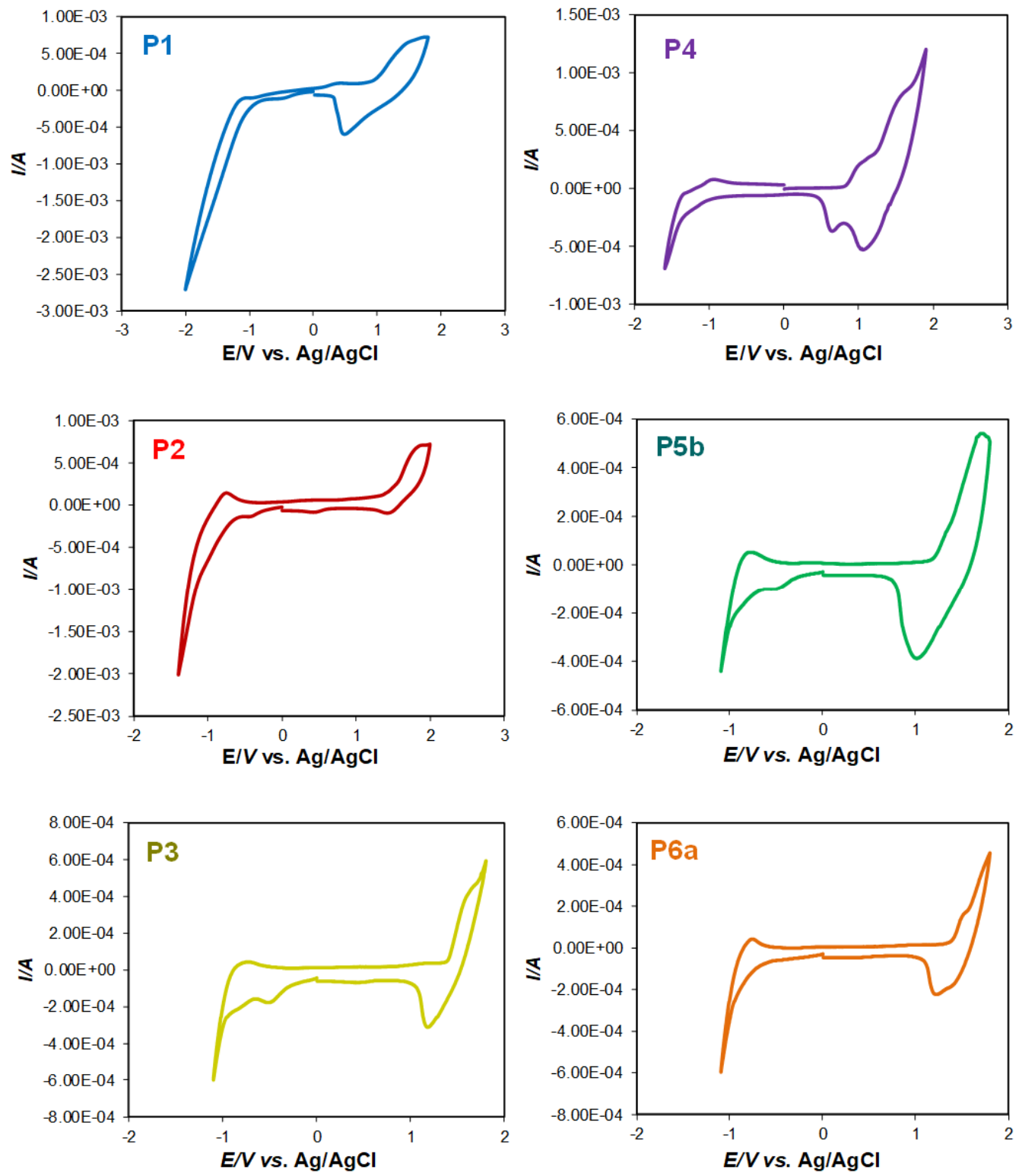

Figure S23. Cyclic voltammograms of polymers. 
(a)

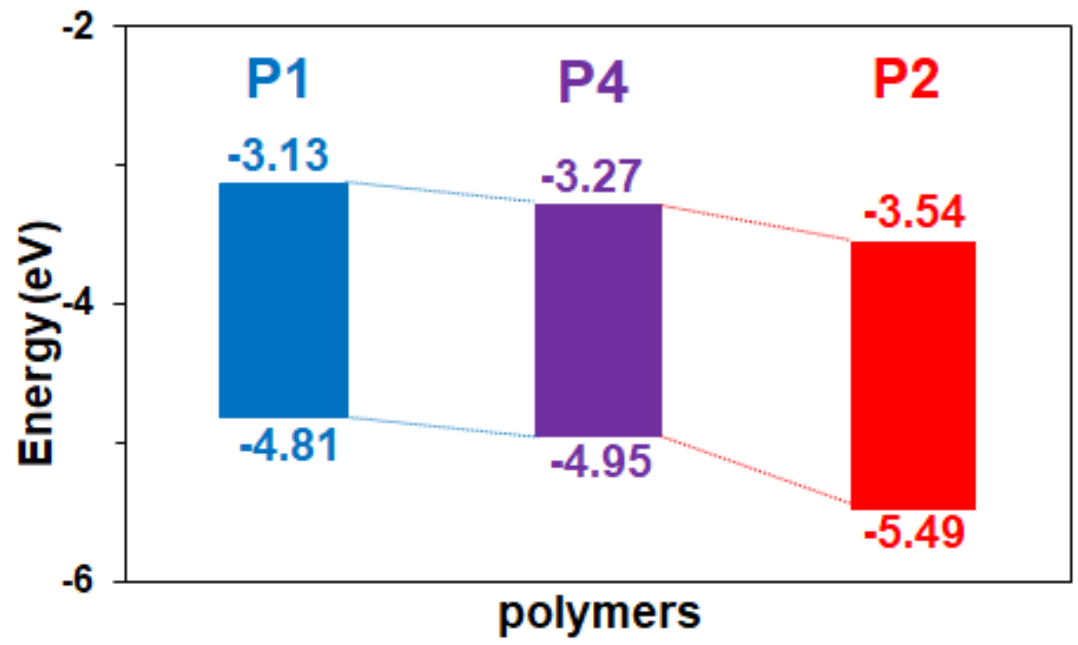

(b)

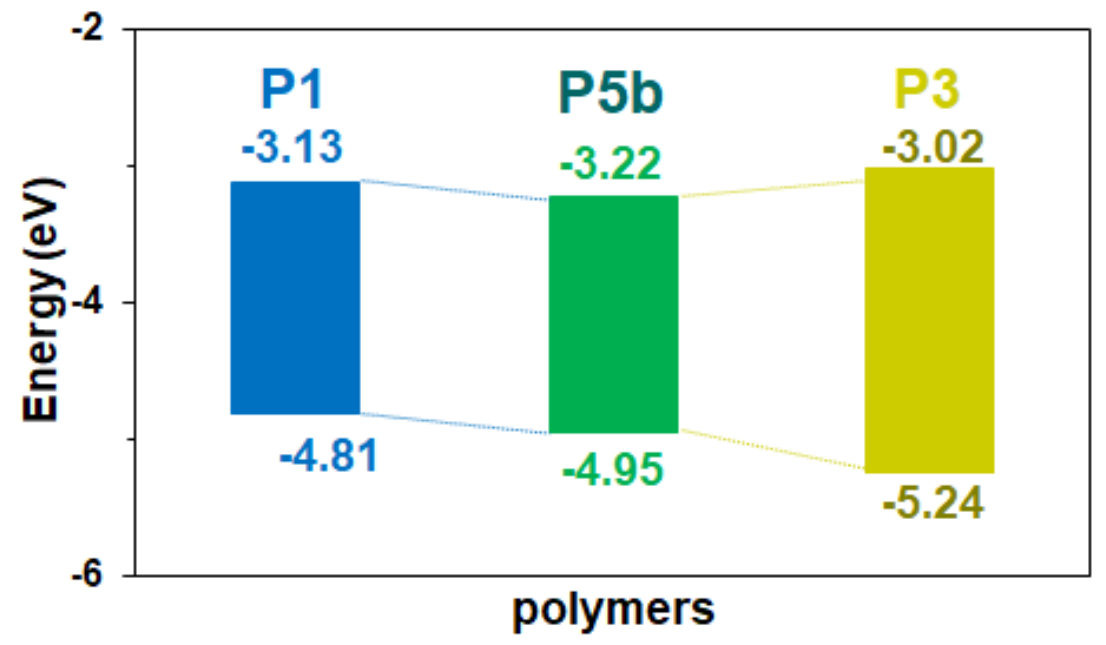

(c)

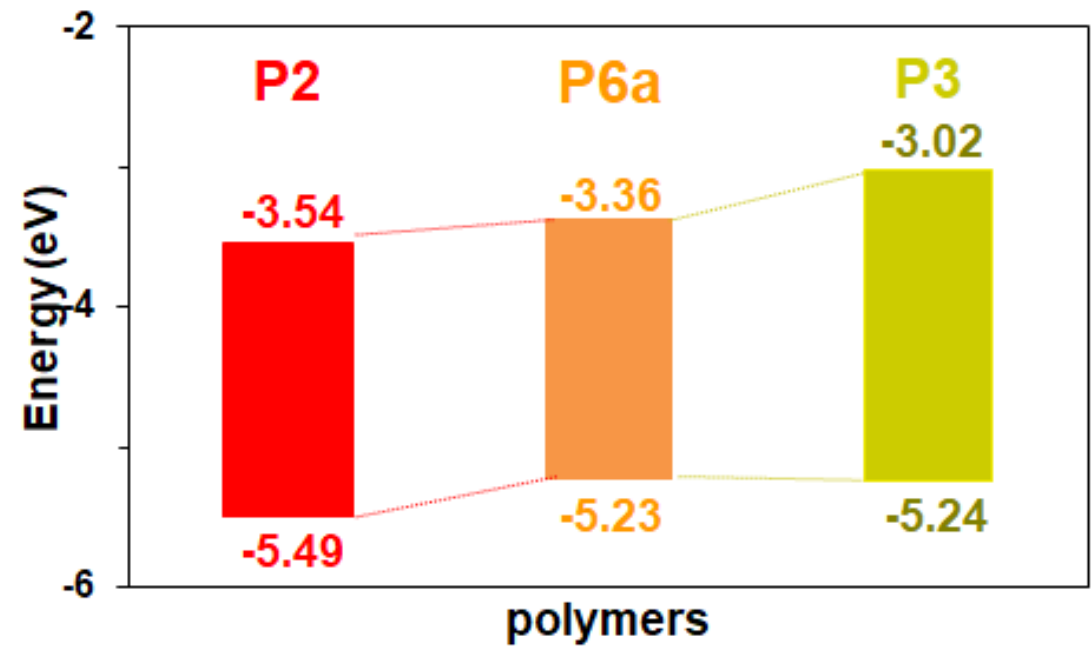

Figure S24. Energy diagrams of (a) P1, P4, and P2, (b) P1, P5, and P3, and (c) P2, P6, and P3. 
To verify the electronic state, the molecular orbitals were calculated using density functional theory (DFT) for the simulated molecular models of the predicted oligomers produced by ROMP (Figures S25 and S26). The LUMO distributions for CPDT-BT, corresponding to a component of the P5 structure, show widely delocalized electronic states through the whole molecule, whereas the HOMO distributions show delocalized states in the CPDT unit. These results suggest that the influence of the CPDT-vinylene unit on HOMO is more significant than that of the BT-vinylene unit. On the contrary, the LUMO distributions for BT-DTBT, corresponding to a component of the P6 structure, show localized electronic states on the benzothiadiazole unit in the DTBTvinylene unit, whereas the HOMO distributions show widely delocalized electronic states through the BT-vinylene unit, suggesting that the benzothiadiazole group contributes to a significant lowering of LUMO in this configuration. The energy diagrams calculated using DFT exhibit similar trend to the experimental values (Figure S26).
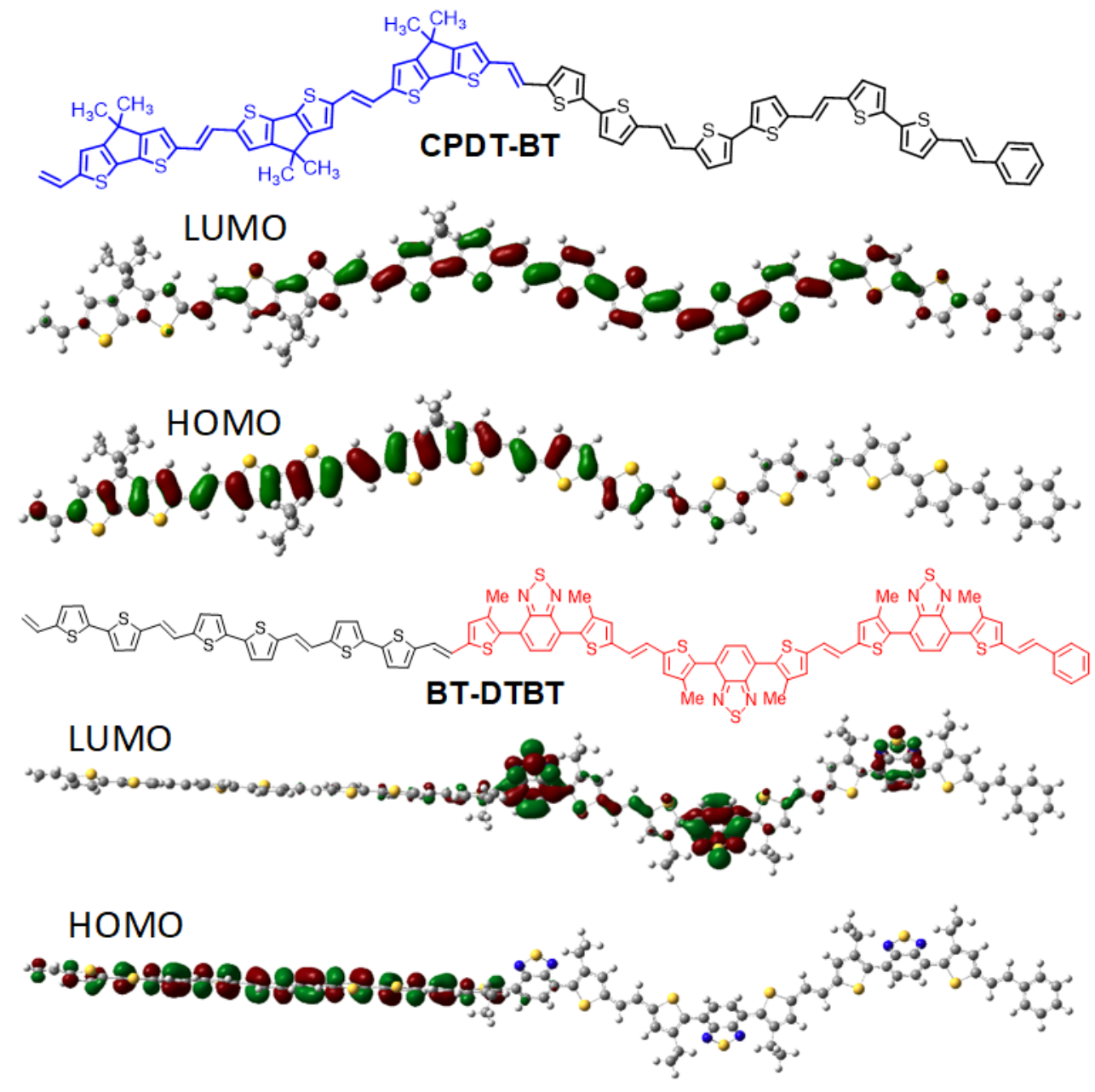

Figure S25. Molecular orbital calculation using DFT. 

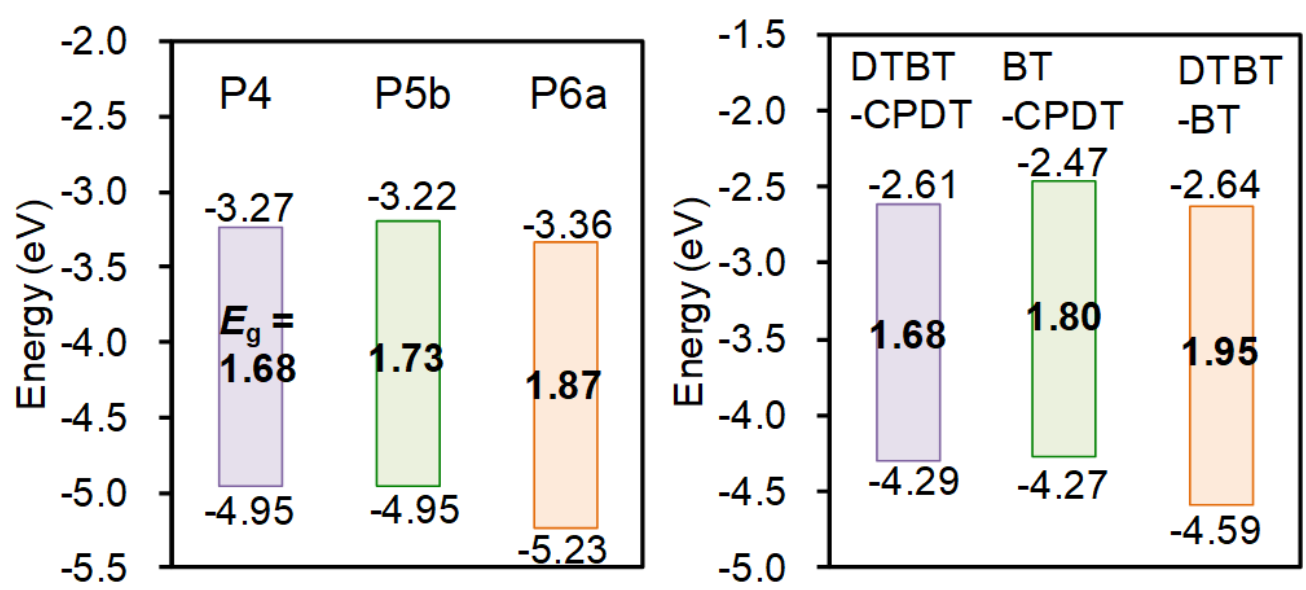

Figure S26. Energy diagrams of polymers estimated by CVs and UV-Vis spectra (left) and molecular orbital calculation using DFT (right). 


\section{DSC}
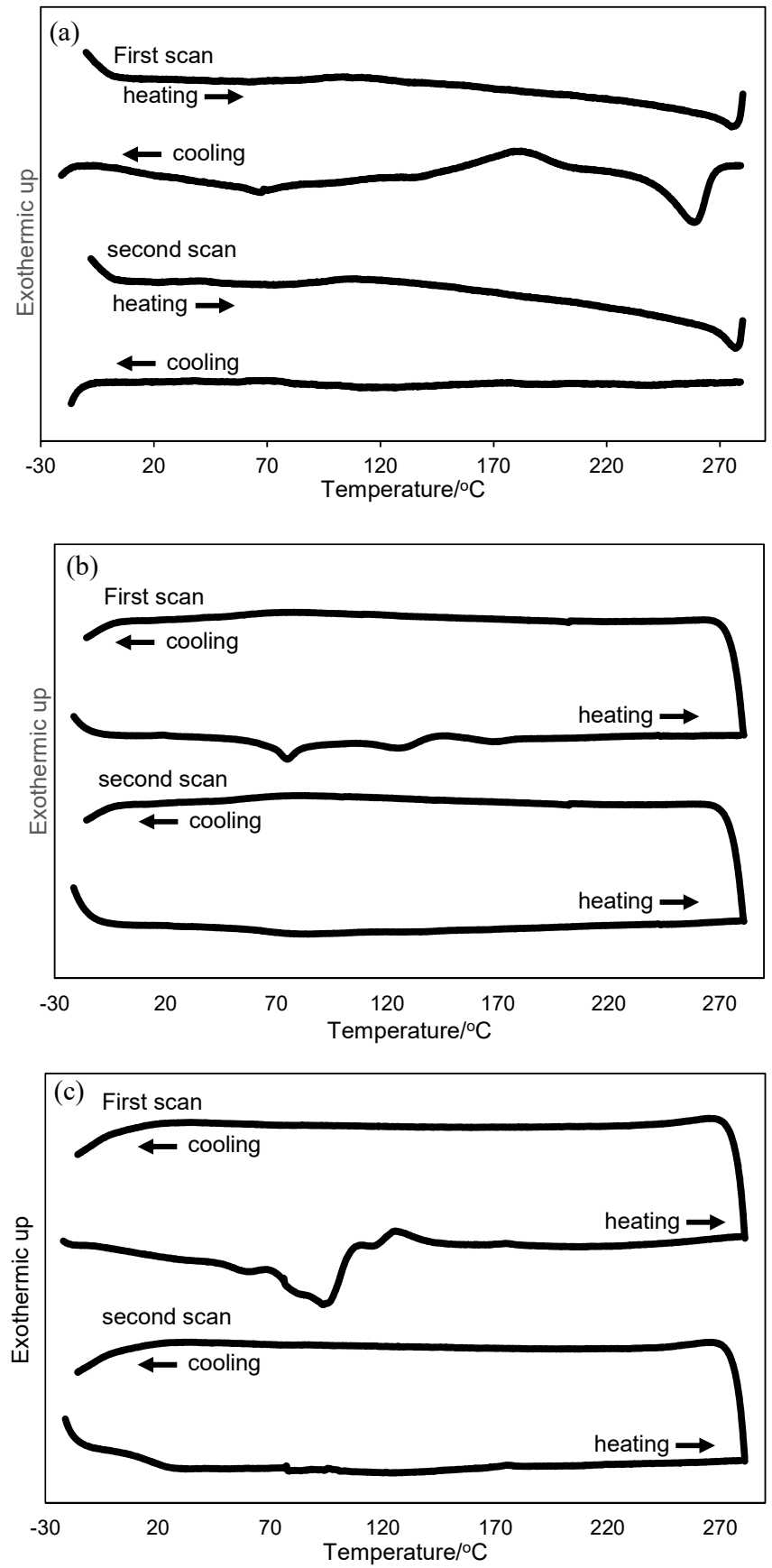

Figure S27. DSC charts of (a) P1, (b) P2, and (c) P3 under a nitrogen atmosphere (scan rate $\left.=20^{\circ} \mathrm{C} \mathrm{min}^{-1}\right)$. These charts show endothermic peaks for enthalpy relaxation in the first scan, but they are disappeared in the second scan, showing amorphous properties. 


\section{AFM}

(a)

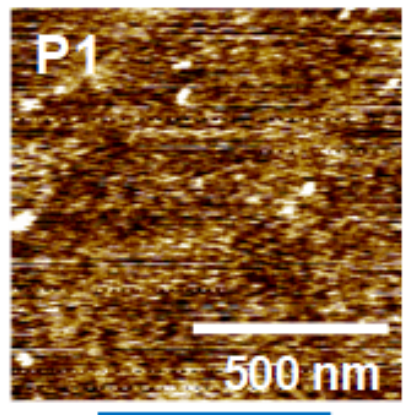

(d)

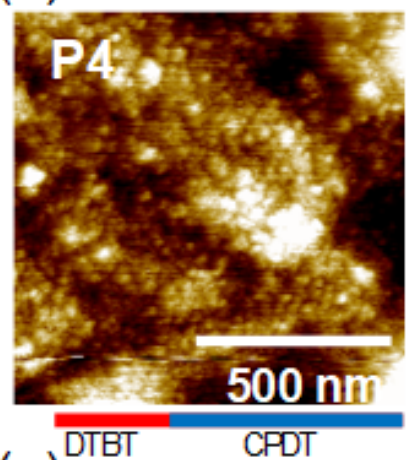

(g)

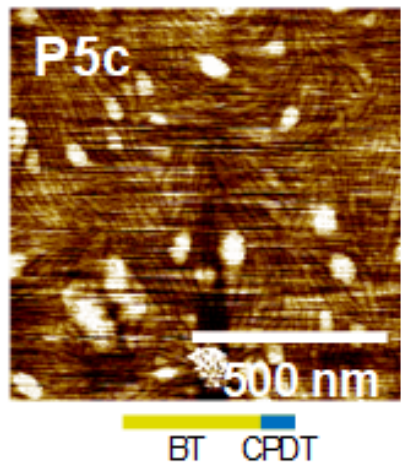

(b)

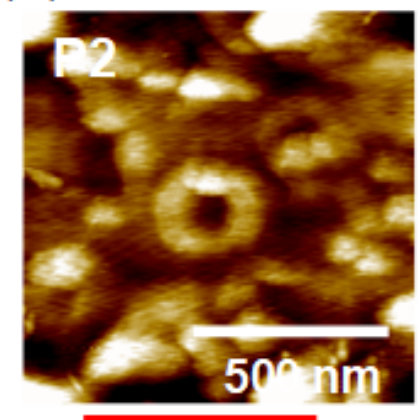

(e)

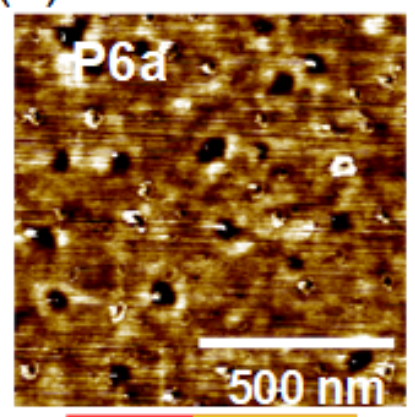

(h)

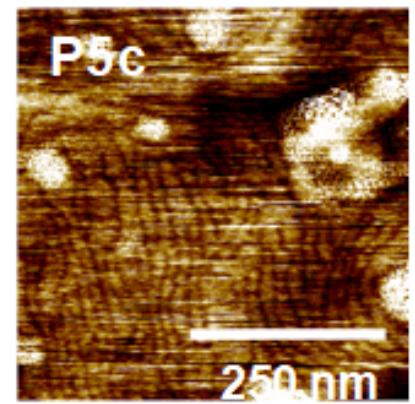

BT CPDT (c)

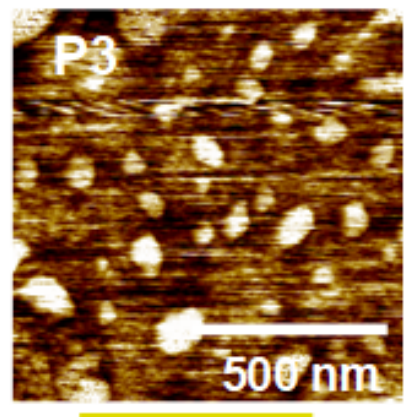

(f)

BT

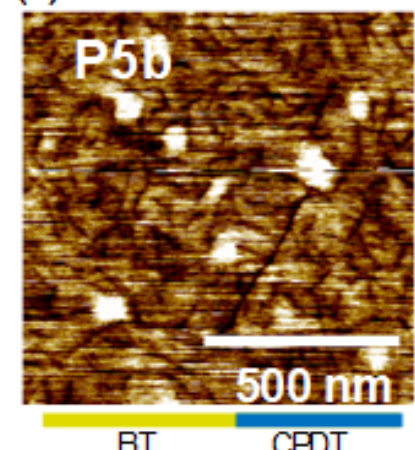

(i)

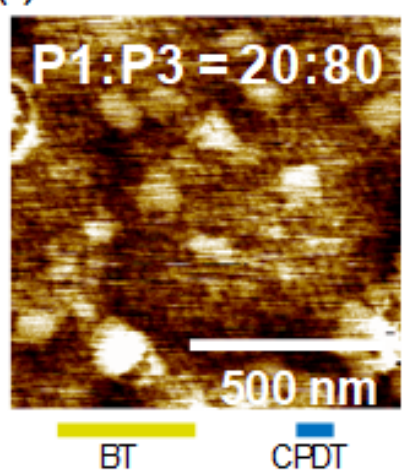

Figure S28. AFM topographic images of polymers (a) P1, (b) P2, (c) P3, (d) P4, (e) P6a, (f) P5b, (g) P5c with a range of $1 \times 1 \mu \mathrm{m}^{2}$ and (h) P5c with a range of $0.5 \times 0.5$ $\mu \mathrm{m}^{2}$, and (i) a mixture of $\mathbf{P 1}$ and $\mathbf{P 3}$ with a molar ratio of P1:P3 $=20: 80$. The rectangles below the images represent the approximate $M_{\mathrm{n}}$ of each unit. 


\section{GISAXS and GIWAXS}

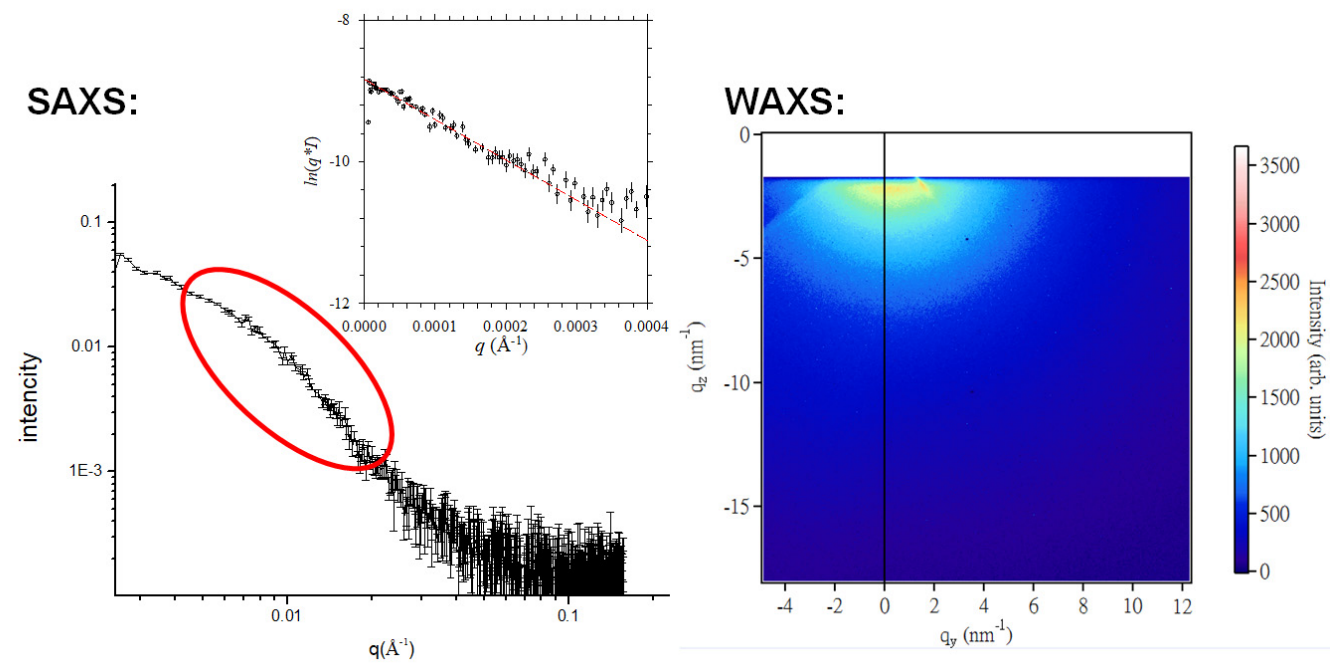

Figure S29. In-plane GISAXS profile and the rod-like model fitting (dashed line in the inset of the same data in the Kratky-Porod presentation) for the P5c film. Also shown in the right-hand-side is the corresponding GIWAXS pattern, of no obvious crystalline reflections.

SAXS:

WAXS:
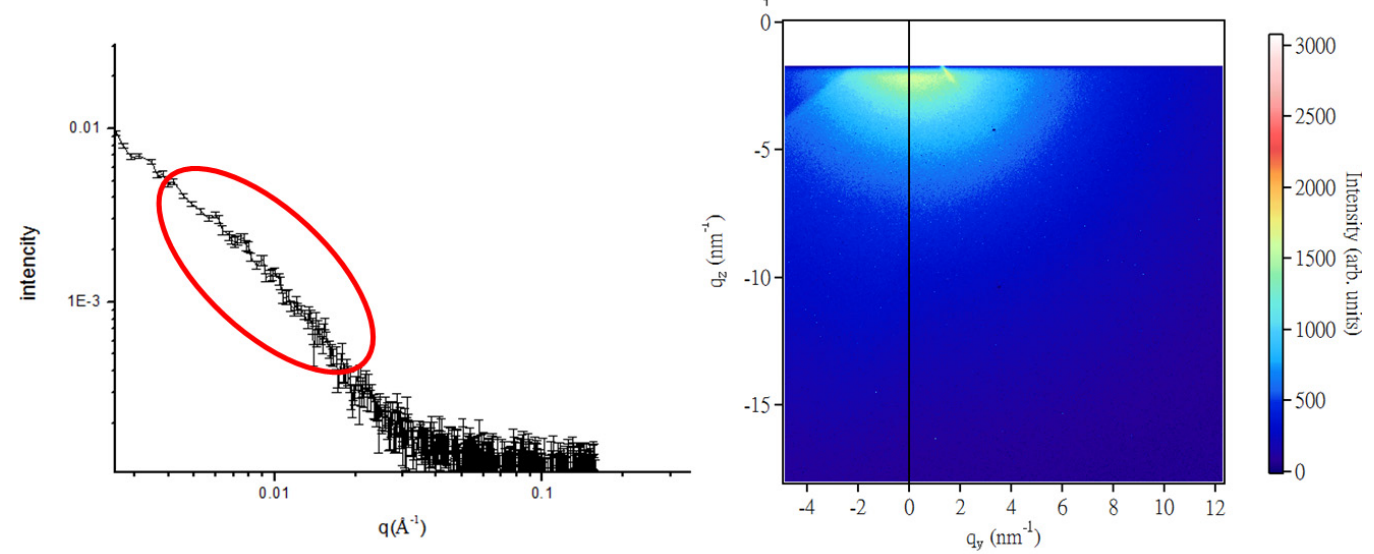

Figure S30. In-plane GISAXS profile and the 2D GIWAXS for the P1 film. 